\title{
CRISIS O COMPLEJIDAD DEL SISTEMA DE FUENTES DEL DERECHO EN COLOMBIA: PROBLEMAS Y DESAFÍOS DEL DERECHOSUSTANCIAL Y PROCESAL JURISPRUDENCIAL *
}

\author{
Complexity or crisis of the sources of law system in Colombia: issues \\ and challenges according to substantive law and procedural law in \\ case law
}

Diego Armando Yañez Meza**, Liliana Damaris Pabón Giraldo***

Carlos Alberto Colmenares Uribe ${ }^{* * * *}$

Recepción: 28 de abril de 2021. Aceptación: 24 de agosto de 2021

DOI: http://dx.doi.org/10.21017/Rev.Repub.2021.v31.a114

* Artículo inédito. El presente artículo de investigación e innovación hace parte del proyecto de investigación «Configuración de la cláusula general de fuentes del derecho en Colombia, a partir del sistema de medios de control de la actividad de los particulares y las autoridades», desarrollado en el Doctorado en Derecho Procesal Contemporáneo de la Universidad de Medellín. El autor hace parte del Grupo de Investigación en Derecho Público y Semillero de Investigación en Derecho Administrativo «Louis Antoine Macarel» de la Universidad Libre, Seccional Cúcuta, Colombia. El autor agradece la contribución al proceso investigativo de Fabián Andrés Montaguth Rincón, Miguel Eudoro Montaguth Rincón, Luisa María Maffi David, Yaritza Fernanda Tarazona Castellanos y Leidy Tatiana Mora Mendoza como auxiliares de investigación. El autor hace referencia a que algunos resultados preliminares frente al objeto de investigación fueron publicados en: Yáñez Meza, D. A. (2017). El derecho al reajuste pensional de la Ley 6 del año 1992: un dilema jurídico para la administración pública territorial desde el derecho de los jueces. Revista Advocatus, 14 (28), 45-77.

** Abogado, Universidad Libre, Seccional Cúcuta. Especialista en Derecho Público, Universidad Externado de Colombia. Magíster en Derecho Administrativo (Investigativa), Universidad Externado de Colombia. Magíster en Derecho Procesal Contemporáneo (Investigativa), Universidad de Medellín. Doctor (C) en Derecho Procesal Contemporáneo, Universidad de Medellín. Autor de distintos libros y artículos de investigación. Director del Centro Seccional de Investigaciones de la Universidad Libre, Cúcuta. Docente en la cátedra Derecho Administrativo general y colombiano e investigación I. Conjuez del Tribunal Administrativo del Norte de Santander. Miembro del Instituto colombiano de Derecho Procesal. Correo electrónico: diego.yanez@unilibre.edu.co; diegoymezabogado@gmail.com

*** Abogada, Universidad de Medellín. Magíster en Derecho Procesal Contemporáneo, Universidad de Medellín. Magíster en Derecho Procesal Garantista, Universidad Nacional de Rosario. Doctora en Derecho, Universidad Nacional de Rosario. Correo electrónico: 1dpabon@udem.edu.co

**** Abogado, Universidad Libre, Seccional Cúcuta. Especialista en Derecho Constitucional, Derecho Penal y Criminología, Derecho de Familia, y Docencia Universitaria. Magíster en Derecho Procesal Contemporáneo (Investigativa), Universidad de Medellín. Doctor (C) en Administración, Hacienda y Justicia en el Estado Social, Universidad de Salamanca. Autor de distintos libros y artículos de investigación. Presidente del Capítulo Norte de Santander del Instituto Colombiano de Derecho Procesal. Correo electrónico: carlosa.colmenaresu@unilibre.edu.co; colmenaco@gmail.com 


\section{RESUMEN}

El sistema normativo en Colombia y su problemática en la aplicación por cualquier sujeto de derechos puede ser comprendido desde un contexto de crisis o de complejidad, dadas las múltiples tipologías de fuentes que necesariamente interactúan y, principalmente, a causa de la jurisprudencia, donde permanentemente se encuentran en tensión, además de la concreción de esa interacción, entre otros, el derecho a la igualdad y los principios de seguridad jurídica y de previsibilidad del derecho, los cuales resultan estructurales para cualquier sociedad políticamente organizada que se declare constitucionalmente como Estado Social de Derecho.

Por lo anterior, esta investigación tiene como objeto la caracterización y la sistematización del derecho que desde la jurisprudencia se crea a partir de subreglas que definen contenidos sustanciales y procesales para cualquier asunto a partir de un estudio de caso, precisando esas situaciones que evidencian ese estado de crisis o complejidad en el sistema normativo y su efecto de cara al propósito final de esta investigación que se compone de tres partes (Parte I, Parte II y Parte III), respecto a la configuración de la que hemos denominado cláusula general de fuentes del derecho para Colombia.

Palabras clave: crisis, complejidad, fuentes del derecho, sistema normativo, jurisprudencia, derecho sustancial, derecho procesal, cláusula general de fuentes del derecho.

\section{ABSTRACT}

The legal system in Colombia and its issue to be enforceable for any person, it may be known from a context of crisis or complexity, all about the various typologies of sources that mainly work according to case law, where they are constantly in tension, in addition to their concretion of that interaction, among others, the right to equal protection and the principles of legal certainty and predictability of law, all of them are the basis for any well-organized society that can be declared constitutionally as a rule of law.

Therefore, this research aims to the characterization and systematization of law from case law that is created from sub-rules that define substantive and procedural contents for any issue according to the case study, all of those situations have shown the current crisis status and the complexity in the legal system and their effect to produce the final aim of this research composed by three parts (part I, part II and part III), all according to the term that we have named general clause of the sources of law in Colombia.

Key words: crisis, complexity, sources of law, legal system, case law, substantive law, procedural law, general clause of the sources of law. 


\section{INTRODUCCIÓN}

En Colombia la administración pública - en adelante AP —, tanto a nivel nacional como territorial, se ha enfrentado desde el año 1993 y aún podría encontrarse en el año 2021, frente al dilema respecto a la aplicación o inaplicación del reajuste pensional creado por el legislador (Ley 6, 1992) en junio 30 del año 1992, el cual fue reglamentado (Decreto 2108, 1992) el 29 de diciembre de igual anualidad: i) a los servidores públicos del orden nacional y, con una mayor discusión del orden territorial, dada la referencia expresa de la disposición Ley - que crea el derecho, frente a tenerse como destinatarios exclusivos del mismo a los pensionados del «sector público nacional»; ii) a los trabajadores oficiales o exclusivamente a los empleados públicos; iii) la crisis que sobre su aplicación se ha configurado, a cuenta de las diferentes y antagónicas tesis jurisprudenciales existentes desde la Corte Suprema de Justicia - en adelante CSJ - y el Consejo de Estado - en adelante CE - y iv) la complejidad sobre un criterio que permita establecer normativamente a partir de la estructura de la jurisdicción (Yáñez Meza, 2013) en Colombia, cómo opera la creación del derecho sustancial y procesal jurisprudencial y si existe algún criterio jerárquico u otro en el interior de la jurisdicción.

Al respecto, distintos medios de comunicación han expuesto la problemática a instancias de los jueces y de las administraciones públicas en sede administrativa en los siguientes términos: i) el 2 de marzo del año 2007, «Gobernador del Valle en aprietos porque no se realizó reajuste pensional» (Eltiempo.com, 2007); ii) el 30 de agosto del año 2011, «Enredos de la Ley que permite reajuste pensional» (ElPaís.com.co, 2011); iii) el 12 de mayo del año 2015, «Fiscalía acusa a exalcalde de Cúcuta por prevaricato y peculado» (Fiscalía, Fiscalía acusa a exalcalde de Cúcuta por prevaricato y peculado, 2015); iv) el 13 de mayo del año 2015, «Acusado exalcalde de Cúcuta por conciliación con pensionados» (Semana, 2015); v) el 20 de octubre del año 2016, «Pensionados de la licorera no recibirán pago de Ley $6 .{ }^{\text {ta }}$ por fallos que niegan reajuste» (RadioRodadero, 2016); vi) el 12 de diciembre del año 2017, «Condenan a exalcaldesa de Cúcuta, María Eugenia Riascos» (LaOpinión, Condenan a exalcaldesa de Cúcuta María Eugenia Riascos, 2017); vii) el 14 de diciembre del año 2017, «Privado de la libertad abogado condenado por pago irregular de pensiones en la Alcaldía de Cúcuta» (Fiscalía, 2017); viiii) el 15 de diciembre del año 2017, «CTI captura abogado vinculado a investigación por pago pensional en el municipio» (CaracolRadio, 2017); ix) el 16 de enero del año 2018, «Exalcaldesa de Cúcuta deberá pagar 10 años de prisión. El fallo será apelado por la defensa» (LaW, 2018); x) el 16 de enero del año 2018, «Abogados defienden pago de reajuste a jubilados en 2008» (LaOpinión, 2018); xi) el 17 de enero del 2018, «Condenan a 10 años de prisión a exalcaldesa de Cúcuta por pago irregular en pensiones» (Canal1, 2018); xii) el 15 de noviembre del 2018, «Por el caso de los pensionados, 
absuelven al exalcalde Villasmil» (LaOpinión, 2018); xiii) el 18 de junio del 2019, «Convocan a jubilados para reconocimiento al reajuste pensional» (Calibuenanoticia, 2019).

La Ley 6 del año 1992, específicamente en el artículo 116, establece la única disposición sustancial aplicable en el asunto desde la fuente formal Ley y constituye el punto de partida en la problemática que se presenta. En esta se consagró el siguiente texto:

\begin{abstract}
Artículo 116. AJUSTE A PENSIONES DEL SECTOR PÚBLICO NACIONAL. Para compensar las diferencias de los aumentos de salarios y de las pensiones de jubilación del sector público nacional, efectuados con anterioridad al año 1989, el Gobierno Nacional dispondrá gradualmente el reajuste de dichas pensiones, siempre que se hayan reconocido con anterioridad al $1 .^{\circ} \mathrm{de}$ enero de 1989.
\end{abstract}

Los reajustes ordenados en este artículo comenzarán a regir a partir de la fecha dispuesta en el decreto reglamentario correspondiente, y no producirán efecto retroactivo.

\title{
(Subraya fuera del texto original)
}

Como se advierte, a partir de este contenido no cabe la menor duda de que los sujetos a quienes resulta aplicable el ajuste son aquellos pensionados del «sector público nacional», quienes además de este requisito, debían acreditar haber adquirido su derecho a la pensión hasta el 31 de diciembre del año 1988, inclusive; en otros términos, contar con un acto administrativo de carácter particular en el que se le reconociera el derecho a la pensión y consecuentemente su condición de pensionado a esa fecha.

El fin del ajuste que el legislador creó desde esta Ley se encuentra en «corregir desequilibrios y desigualdades que habían sido provocados por la existencia, en el pasado, de diferentes sistemas de reajuste pensional» ${ }^{1}$, por lo que una vez publicada la Ley, el pensionado que considerara cumplir estos requisitos podía iniciar una actuación administrativa en ejercicio del derecho de petición en interés particular, ante las entidades de previsión social o los organismos o

1 Esta justificación fue expuesta por la Corte Constitucional en providencia (Sentencia C531, 1995), motivación que fue retomada por el Consejo de Estado (Sentencia NPI 0038(479)/98, 1999).

Dentro de los sistemas a los que seguramente hacen referencia la CC y el CE, se identificarían principalmente los creados a partir de las siguientes disposiciones: Ley 4 de 1976, Ley 71 de 1988, Ley 6 de 1992, Ley 100 de 1993 y sus disposiciones reglamentarias. 
entidades que están encargadas del pago de las pensiones de jubilación, en búsqueda de su reconocimiento y posterior pago. Sin embargo, sobre esta Ley y su correspondiente Decreto Reglamentario, no son pocos los problemas sustanciales y procesales que se presentan en la aplicabilidad del ajuste; tal como pasa a detallarse, se trata de un asunto complejo dada la interacción de diferentes fuentes del derecho y de distintos órganos que las profieren, teniendo en cuenta las siguientes consideraciones:

1. El Congreso de la República expide la Ley 6, «Por la cual se expiden normas en materia tributaria, se otorgan facultades para emitir títulos de deuda pública interna, se dispone un ajuste de pensiones del sector público nacional y se dictan otras disposiciones», el 30 de junio del año 1992, la cual es publicada en el Diario Oficial n. ${ }^{\circ} 40490$ en igual fecha ${ }^{2}$.

2. La Presidencia de la República en virtud del mandato al ejecutivo establecido en el inciso segundo del artículo 116 de la Ley y en ejecución de su potestad reglamentaria, expide el Decreto 2108, el 29 de diciembre del año 1992, «Por el cual se ajustan las pensiones de jubilación del sector público en el orden Nacional», el cual fue publicado en el Diario Oficial n. ${ }^{\circ} 40703$, el 31 de diciembre del año $1992^{3}$.

En este se consagró el siguiente texto:

Artículo 1. ${ }^{\circ}$. Las pensiones de jubilación del sector público del orden nacio-

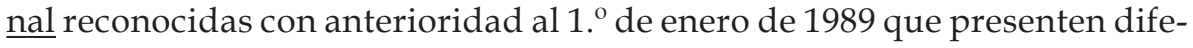
rencias con los aumentos de salarios serán reajustadas a partir del $1 .^{\circ}$ de enero de 1993, 1994 y 1995 así:

\begin{tabular}{|c|ccc|}
\hline $\begin{array}{c}\text { Año de causación del } \\
\text { derecho a la pensión }\end{array}$ & \multicolumn{3}{|c|}{ Porcentaje del reajuste } \\
1993 & $-\mathbf{1 9 9 4}-$ & $\mathbf{1 9 9 5}$ \\
\hline 1981 y anteriores 28\% distribuidos así: & 12,0 & 12,0 & 4,0 \\
\hline 1982 hasta 1988 14\%, distribuidos así: & 7,0 & 7,0 & \\
\hline
\end{tabular}

Artículo 2. ${ }^{\circ}$. Las entidades de previsión social o los organismos o entidades que están encargadas del pago de las pensiones de jubilación tomarán el valor de la pensión mensual a 31 de diciembre de 1992 y le aplicarán el

2 Debe indicarse que la tipología normativa de esta Ley es la de Ley ordinaria.

3 Debe indicarse que la tipología normativa de este Decreto es la de Decreto ordinario. 
porcentaje del incremento señalado para el año de 1993 cuando se cumplan las condiciones establecidas en el artículo $1 .^{\circ}$.

El 1. ㅇ de enero de 1994 y 1995 se seguirá igual procedimiento con el valor de la pensión mensual a 31 de diciembre de los años 1993 y 1994 respectivamente, tomando como base el porcentaje de la columna correspondiente a dichos años señalada en el artículo anterior.

Estos reajustes pensionales son compatibles con los incrementos decretados por el Gobierno Nacional en desarrollo de la Ley 71 de 1988.

Artículo 3. ${ }^{\circ}$. El reconocimiento de los reajustes establecidos en el artículo $1 .^{\circ}$ no se tendrá en cuenta para efectos de la liquidación de mesadas atrasadas.

Artículo $4{ }^{\circ}$. Los reajustes ordenados en el presente decreto comenzarán a regir a partir de las fechas establecidas en el artículo $10^{\circ}$ y no producirán efectos retroactivos.

(Subraya fuera del texto original)

Nuevamente en la disposición reglamentaria se reitera en dos segmentos que los sujetos respecto de los cuales opera el ajuste son aquellos vinculados al «sector público del o en el orden nacional», definiendo la gradualidad en la aplicación del ajuste a partir de periodos exactos (desde cada mes de enero de los años 1993 a 1995) y los porcentajes de incrementos que debían operar en los mismos (28\% y $14 \%$ ), dependiendo del año de causación y reconocimiento del derecho a la pensión.

3. La Corte Constitucional - en adelante CC - en providencia (Sentencia C531, 1995) del 20 de noviembre del año 1995, resolvió: «Declarar INEXEQUIBLE el artículo 116 de la Ley 6. a de 1992».

4. La Corte Constitucional en providencia (Sentencia C-009, 1996) del 18 de enero del año 1996, resolvió: «ESTESE A LO RESUELTO en la sentencia Nro. C-531 del 20 de noviembre de 1995 que declaró INEXEQUIBLE el artículo 116 de la Ley 6. ${ }^{a}$ de 1992».

5. El Consejo de Estado en providencia (Sentencia NPI 11636, 1998) del 11 de junio del año 1998, resolvió: «Declárese nulo [...] el artículo 1. ${ }^{\circ}$ del Decreto 2108 del mismo año».

Debe aclararse que el medio que se usó técnicamente en este asunto para el control del Decreto 2108 de 1992 fue el de nulidad por inconstitucionalidad, 
proceso que termina con una sentencia NPI, aunque en el texto de esta sentencia se haga referencia expresa al ejercicio de una «...acción de nulidad...» o de simple nulidad, cuyo proceso finaliza con una sentencia $\mathrm{N}^{4}$.

6. El Consejo de Estado en providencia (Sentencia NPI 0038-(479)/98, 1999) del 15 de abril del año 1999, resolvió: «2. Declárase la nulidad de los artículos 2. ${ }^{\circ}, 3^{\circ}$ y $4 .^{\circ}$ del Decreto 2108 de 1992».

De igual forma, sobre esta sentencia debe indicarse que sustancialmente trata una tipología de sentencia NPI, es decir, en el fondo configura un trámite y decisión de nulidad por inconstitucionalidad, aunque en el texto de la sentencia se haga referencia expresa al ejercicio de una «demanda de simple nulidad», la cual finaliza con una sentencia de tipología N.

Con todo lo anterior, se está frente a una problemática donde la disposición que crea el derecho al ajuste pensional ha sido declarada INEXEQUIBLE y la disposición que reglamenta el mismo ha sido posterior y materialmente ${ }^{5}$ declarada NULA POR INCONSTITUCIONAL. Por ello, de conformidad con el artículo 243 de la Constitución Política de 1991 — en adelante CP — , «Ninguna autoridad podría reproducir el contenido material del acto jurídico declarado inexequible por razones de fondo», en cuanto «los fallos que la Corte dicta en ejercicio del control jurisdiccional hacen tránsito a cosa juzgada constitucional.» ${ }^{6}$. Así las cosas, la aplicabilidad del derecho al ajuste pensional no

4 De conformidad con lo dispuesto en el artículo 97 (Decreto 01, 1984), una de las funciones especiales de la Sala Plena de lo Contencioso Administrativo era conocer y decidir a través del procedimiento ordinario establecido en el artículo 206: «7. De las acciones de nulidad por inconstitucionalidad que se promuevan contra los decretos de carácter general dictados por el Gobierno Nacional, que no correspondan a la Corte Constitucional, cuya inconformidad con el ordenamiento jurídico se establezca mediante confrontación directa con la Constitución Política y que no obedezca a función propiamente administrativa.»

Esta función se ratificó por el constituyente (Constitución Política, 1991) al consagrar en el artículo 237 que «Son atribuciones del Consejo de Estado: [...] 2. Conocer de las acciones de nulidad por inconstitucionalidad de los decretos dictados por el Gobierno Nacional, cuya competencia no corresponda a la Corte Constitucional.»

5 Se hace referencia a una declaración material como contraposición a una declaración formal en la medida en que expresamente en la parte resolutiva de las sentencias del Consejo de Estado del 11 de junio de 1998 y del 15 de abril de 1999, no se consignó la expresión «Declárese nulo por inconstitucional» del Decreto 2108 del año 1992.

6 Sobre los efectos del fallo en la nulidad por inconstitucionalidad, a pesar de que en el artículo 189 (Ley 1437, 2011) se dispuso que «Las sentencias de nulidad sobre los actos proferidos en virtud del numeral 2 del artículo 237 de la Constitución Política, tienen efectos hacia el futuro y de cosa juzgada constitucional. Sin embargo, el juez podrá disponer unos efectos diferentes», con lo cual estas también tendrían efectos de cosa 
sería posible dado que un acto administrativo no puede tener como fundamento de derecho disposiciones INEXEQUIBLES y a su vez NULAS POR INCONSTITUCIONALES.

Además de lo expuesto, este contexto resulta aún más complejo en atención a los tiempos en los que cada fuente del derecho referida atrás se ha expedido y publicado, con los efectos que le son propios en cuanto a su vigencia, derogatoria o tránsito, tanto desde el punto de vista del pensionado que puede iniciar la actuación administrativa en ejercicio del derecho de petición en interés particular, como de la entidad de previsión social o el organismo o entidad que está encargada del pago de la pensión de jubilación que debe resolver.

Desde el mismo momento en que la Ley se publica, las personas pudieron haber iniciado la actuación administrativa, aunque aún no hubiera sido expedido el decreto reglamentario; luego, una vez es publicado, podrían haber iniciado nuevas actuaciones y otras estarían en trámite, al punto en que, para el 20 de noviembre del año 1995, fecha en la cual es declarado inexequible el artículo 116, muchas de ellas habrían sido resueltas y otras se encontrarían pendientes. Posteriormente, incluso luego de emitida la decisión (Sentencia C-531, 1995) se siguieron iniciando actuaciones administrativas, debiendo considerarse la misma situación de antes y después, respecto a la expedición y publicación de las providencias (Sentencia C-009, 1996) de la Corte Constitucional y las sentencias del Consejo de Estado NPI 11636 de 1998 y NPI 0038-(479)/98 de 1999.

Todas estas hipótesis de aplicación son ciertas hasta llegar a la actualidad7, momento en el que aún es posible que pensionados puedan solicitar la aplicación del derecho al ajuste pensional creado en la Ley 6 del año 1992 o que se encuentren actuaciones administrativas en trámite o que agentes y exagentes de las administraciones públicas se encuentren en trámite de procesos penales o en acciones de repetición, por haber reconocido y pagado

juzgada constitucional, la Corte Constitucional declaró inexequible la expresión «constitucional» (Sentencia C-400, 2013), por lo que técnicamente ha de conocerse que estos fallos hacen tránsito a «cosa juzgada» y no a «cosa juzgada constitucional». Al respecto cabría cuestionarse: ¿existe de fondo y en la práctica alguna diferencia entre estos dos conceptos de cosa juzgada?; así mismo, teniendo en cuenta la identidad material entre el juicio de control abstracto de constitucionalidad que ejerce la Corte Constitucional y el que ejerce el Consejo de Estado en el control abstracto de nulidad por inconstitucionalidad, ¿se justifica la inexequibilidad declarada por la CC?

7 Se hace referencia a diciembre del año 2019. A partir de la búsqueda exhaustiva del conjunto de providencias sobre este asunto, se puede afirmar que no se han emitido sentencias en el año 2020. 
un derecho con base en disposiciones INEXEQUIBLES y NULAS POR INCONSTITUCIONALES.

Finalmente, este contexto se complejiza aún más si se tiene en cuenta que, de un lado, frente a estas mismas disposiciones el Consejo de Estado en su Sección Segunda y como resultado de recursos de apelación, ha condenado al Estado en el nivel territorial y dado aplicación al reajuste pensional creado en la Ley 6, como ocurrió en el caso Saturia Jiménez de Duque vs. Departamento del Valle del Cauca (Sentencia NRD 1920-13, 2013) y, de otro, la Corte Suprema de Justicia en su Sala de Casación Laboral, NO CASA las sentencias de los tribunales que no aplican el reajuste pensional respecto a las pensiones del orden territorial, como sucedió en el caso de Fernando Castillo Torres vs. Municipio de Cali (Sentencia CAS-SL 47697, 2014), lo cual configura un grave problema de IGUALDAD, dado que, en últimas, el reconocimiento del derecho depende entonces del órgano al cual le compete el conocimiento del asunto de conformidad a las reglas definidas en la Ley y de si la persona es trabajador oficial o no.

Debe destacarse que un pensionado a noviembre de 1975 recibía como cuantía inicial de la mesada una suma de $\$ 11.219,13^{8}$ pesos, otro a diciembre de 1975 percibía $\$ 3.769,07^{9}$ pesos; así mismo, a noviembre de 1983 podría tenerse como monto inicial de una pensión la suma de $(\$ 51.485)^{10}$ pesos; otra persona jubilada para el mes de septiembre de 1969 podría tener como cuantía inicial de su pensión la suma de $\$ 1.758,89^{11}$ pesos, de lo que debe entenderse que en este asunto se trata del derecho sustancial y procesal de sujetos que ostentan una especial protección constitucional, derechos que se examinarán en primer lugar desde la jurisprudencia de la Sala de Casación Laboral de la Corte Suprema de Justicia (Parte I).

\section{PROBLEMA JURÍDICO}

¿Cómo se configura la cláusula general de fuentes del derecho en Colombia a partir de los problemas y desafíos del derecho sustancial y procesal jurisprudencial, considerando la crisis o complejidad del sistema desde la estructura de la jurisdicción y el asunto del reajuste pensional de la Ley 6 y su Decreto reglamentario 2108 del año 1992, en la Sala de Casación Laboral de la Corte Suprema de Justicia?

8 (Sentencia CAS-SL 29246, 2007).

9 (Sentencia CAS-SL 58896, 2018).

10 (Sentencia CAS-SL 23253, 2004).

11 (Sentencia CAS-SL 47697, 2014). 


\section{ESQUEMA DE RESOLUCIÓN}

La cuestión planteada se resolverá en consideración al siguiente esquema: se aborda el análisis de i) el conjunto de providencias que tratan el asunto desde la Sala de Casación Laboral de la Corte Suprema de Justicia; ii) las tesis entorno al derecho sustancial y procesal jurisprudencial en la jurisdicción ordinaria, especialidad laboral: Juzgados Laborales del Circuito, Tribunales Superiores Sala Laboral y Sala de Casación Laboral de la Corte Suprema de Justicia; iii) la vigencia, derogatoria y tránsito de las disposiciones declaradas inexequibles y nulas; iv) la exclusión en la aplicación del ajuste a los pensionados del orden territorial y la exclusividad del derecho a los pensionados del orden nacional; v) la calidad de los destinatarios del ajuste pensional: la condición de trabajador oficial o empleado público; vi) la carga de la prueba del desajuste de la pensión: ¿carga estática en el demandante o presunción legal que invierte la carga?; vii) la sistematización en la motivación de las tesis jurisprudenciales: creación de subreglas en el asunto concreto $^{12}$. Finalmente, se darán las CONCLUSIONES.

\section{El conjunto de providencias que tratan el asunto desde la Sala de Casación Laboral de la Corte Suprema de Justicia.}

Como se ha evidenciado en la problemática presentada y se detallará en los capítulos sucesivos, el derecho sustancial y procesal que regula el asunto se encuentra en una importante dosis en la fuente formal jurisprudencia, dado el escaso contenido que la fuente formal Ley y el Decreto Reglamentario ofrece para la solución del problema ${ }^{13}$. Así, solo a través del estudio exhaustivo de las providencias de la Corte Constitucional en Sala Plena o de las diferentes Salas de Revisión, de la Sección Segunda del Consejo de Estado en decisiones que se adoptan en segunda instancia y de la Sala de Casación Laboral de la Corte Suprema de Justicia en virtud de la demanda de casación, es posible descubrir, se reitera, el derecho sustancial y el derecho procesal especial en el asunto.

12 El instrumento de investigación utilizado en el análisis estático y dinámico de la jurisprudencia fue la ficha de análisis jurisprudencial propuesta en el libro Método, metodología y técnicas de la investigación aplicadas al derecho (Clavijo Cáceres, Guerra Moreno, \& Yáñez Meza, 2014).

13 En este sentido, pareciera que en esta interacción de fuentes se aplicara una lógica equiparable a la que opera en materia procesal frente a la integración de disposiciones procesales desde el ámbito especial hacia la disposición procesal residual, como por ejemplo ocurre en el ámbito de aplicación laboral y su integración con el Código General del Proceso (Yáñez Meza, 2017). 
De tal forma que resulta imperativo caracterizar la estructura de estas jurisdicciones en Colombia conforme a la Constitución, los órganos que la componen en su más alta jerarquía y las diferentes tipologías de providencias que estos emiten. A partir de estas decisiones, debemos afirmar que se daría encuentro a lo que denominaremos «derecho sustancial/procesal jurisprudencial constitucional», el cual se crea a partir de las subreglas que resuelven el asunto tratándose de providencias que profiera la Corte Constitucional; «derecho sustancial/procesal jurisprudencial contencioso administrativo», frente al Consejo de Estado; y del «derecho sustancial/procesal jurisprudencial ordinario laboral/civil/comercial/familia/ agrario o penal» y de otras especialidades, en el caso de la Corte Suprema de Justicia.

Las providencias de casación (Sentencia CAS-SL) que han abordado el estudio del asunto respecto a la aplicación del reajuste pensional del artículo 116 (Ley 6,1992 ) y su reglamentación (Decreto 2108, 1992) inician en el año 1997 y son en la actualidad las siguientes:

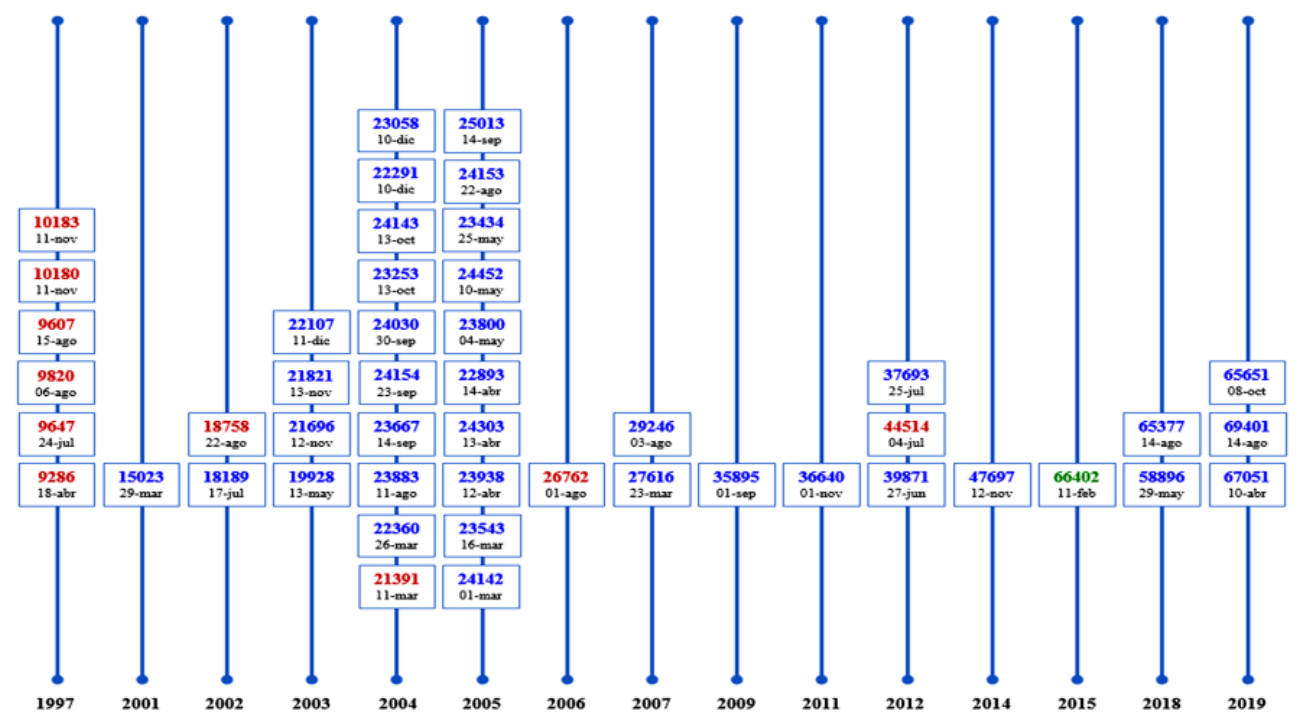

Gráfica 1. Conjunto de providencias que aborda el mismo asunto: ajuste pensional de la Ley 6 del 1992 y su Decreto Reglamentario 2108 de 1992, en la jurisprudencia de la Sala Laboral de la Corte Suprema de Justicia ${ }^{14}$.

Fuente: Elaboración propia del autor.

14 En el año 1997: (Sentencia CAS-SL 9286, 1997) del 18-abr-97, (Sentencia CAS-SL 9647, 1997) del 24-jul-97, (Sentencia CAS-SL 9820, 1997) del 06-ago-97, (Sentencia CAS-SL 9607, 1997) del 15-ago-97, (Sentencia CAS-SL 10180, 1997) del 11-nov-97, (Sentencia CAS-SL 10183, 1997) del 11-nov-97; en el año 2001: (Sentencia CAS-SL 15023, 2001) del 29-mar-01; 
Se trata de 48 providencias de la tipología CAS-SL, destacándose en color rojo los casos decididos sobre órganos del orden nacional, particularmente del BANCO DE LA REPÚBLICA y ECOPETROL, en color azul los casos dados sobre órganos del orden territorial y en color verde un asunto de un trabajador-pensionado de una empresa del sector privado, SHELL COLOMBIA S. A. Como se observa, en un principio la exigibilidad del reajuste se persiguió por los pensionados del sector público nacional, cuyos primeros casos se decidieron en virtud del recurso extraordinario de casación en el año 1997. Solo hasta el año 2001 la CSJ decide el asunto sobre un pensionado de un órgano del orden territorial. Adicional a esta consideración, debe indicarse que independientemente de si el órgano era del orden nacional o territorial, la condición de unos y otros pensionados o su común denominador era la de haber sido trabajadores oficiales.

\subsection{Tesis en torno al derecho sustancial y procesal jurisprudencial en la jurisdicción ordinaria, especialidad laboral: Juzgados Laborales del Circuito, Tribunales Superiores Sala Laboral y Sala de Casación La- boral de la Corte Suprema de Justicia}

Son variadas las tesis que en la estructura de esta jurisdicción se tienen frente al derecho sustancial y procesal en el asunto del ajuste pensional de la Ley 6

en el año 2002: (Sentencia CAS-SL 18189, 2002) del 17-jul-02, (Sentencia CAS-SL 18758, 2002) del 22-ago-02; en el año 2003: (Sentencia CAS-SL 19928, 2003) del 13-may-03, (Sentencia CAS-SL 21696, 2003) del 12-nov-03, (Sentencia CAS-SL 21821, 2003) del 13-nov-03, (Sentencia CAS-SL 22107, 2003) del 11-dic-03; en el año 2004: (Sentencia CAS-SL 21391, 2004) del 11-mar-04, (Sentencia CAS-SL 22360, 2004) del 26-mar-04, (Sentencia CAS-SL 23883, 2004) del 11-ago-04, (Sentencia CAS-SL 23667, 2004) del 14-sep-04, (Sentencia CASSL 24154, 2004) del 23-sep-04, (Sentencia CAS-SL 24030, 2004) del 30-sep-04, (Sentencia CAS-SL 23253, 2004) del 13-oct-04, (Sentencia CAS-SL 24143, 2004) del 13-oct-04, (Sentencia CAS-SL 22291, 2004) del 10-dic-04, (Sentencia CAS-SL 23058, 2004) del 10-dic-04; en el año 2005: (Sentencia CAS-SL 24142, 2005) del 01-mar-05, (Sentencia CAS-SL 23543, 2005) del 16mar-05, (Sentencia CAS-SL 23938, 2005) del 12-abr-05, (Sentencia CAS-SL 24303, 2005) del 13-abr-05, (Sentencia CAS-SL 22893, 2005) del 14-abr-05, (Sentencia CAS-SL 23800, 2005) del 04-may-05, (Sentencia CAS-SL 24452, 2005) del 10-may-05, (Sentencia CAS-SL 23434, 2005) del 25-may-05, (Sentencia CAS-SL 24153, 2005) del 22-ago-05, (Sentencia CAS-SL 25013, 2005) del 14-sep-05; en el año 2006: (Sentencia CAS-SL 26762, 2006) del 01-ago-06; en el año 2007: (Sentencia CAS-SL 27616, 2007) del 23-mar-07, (Sentencia CAS-SL 29246, 2007) del 03-ago-07; en el año 2009: (Sentencia CAS-SL 35895, 2009) del 01-sep-09; en el año 2011: (Sentencia CAS-SL 36640, 2011) del 01-nov-11; en el año 2012: (Sentencia CAS-SL 39871, 2012) del 27-jun-12, (Sentencia CAS-SL 44514, 2012) del 04-jul-12, (Sentencia CAS-SL 37693, 2012) del 25-jul-12; en el año 2014: (Sentencia CAS-SL 47697, 2014) del 12-nov-14; en el año 2015: (Sentencia CAS-SL 66402, 2015) del 11-feb-15; en el año 2018: (Sentencia CAS-SL 58896, 2018) del 29-may-18, (Sentencia CAS-SL 65377, 2018) del 14-ago-18; en el año 2019: (Sentencia CAS-SL 67051, 2019) del 10-abr-19, (Sentencia CAS-SL 69401, 2019) del 14-ago19, (Sentencia CAS-SL 65651, 2019) del 08-oct-19. 
del año 1992 y el Decreto 2108 de igual anualidad. Estas se sistematizarán a partir de la graficación de líneas jurisprudenciales, metodología de análisis de la jurisprudencia (López Medina, 2008), con algunas modificaciones propias, en la que se muestra una pregunta que perfila la configuración de subregla y las opciones hermenéuticas que han servido para resolverla, con su rastreo en todo el conjunto de providencias encontradas. El punto al extremo izquierdo o derecho de la gráfica indica que en esa sentencia se acoge la tesis correspondiente; y si el punto se muestra hacia el centro en color rojo, significa que la cuestión no fue tratada.

\section{ADVERTENCIA METODOLÓGICA Y DE FONDO SOBRE LA SENTEN-} CIA DE CASACIÓN: A cuenta de la técnica de casación el recurrente debe cumplir con la carga de controvertir las «verdaderas conclusiones esenciales» contenidas en la sentencia de segunda instancia que llevaron al Tribunal correspondiente a negar lo pretendido. Esto implica que la demanda de casación debe cumplir con las reglas adjetivas que su planteamiento y demostración requieren, con el fin de que sea susceptible de un estudio de fondo. Conforme a las normas procesales la demanda debe reunir los conocidos como «requisitos de técnica», que al incumplirse pueden conducir a que el recurso extraordinario de casación resulte infructuoso, es decir, con la decisión de NO CASAR o que previamente se emita una providencia de INADMISIÓN.

Por esto, la casación no es un medio de impugnación que otorgue competencia para juzgar el pleito a fin de resolver a cuál de los litigantes le asiste la razón o cuál de las partes tiene la razón desde el derecho sustancial vigente y aplicable, pues la Corte en casación se limita a enjuiciar la sentencia, con el objeto de establecer si el juez de apelaciones al formularla, motivarla y decidir observó las normas jurídicas que estaba obligado a aplicar. Cuando estos requisitos se incumplen la Corte hace referencia o pone de presente en el caso la existencia de «deficiencias técnicas», lo que, en virtud del carácter dispositivo del recurso de casación es insubsanable ${ }^{15}$, llevando por regla general a que el cargo propuesto bien por la vía directa o la indirecta en sus distintas modalidades sea desestimado por la CSJ, sin importar el acierto o desacierto sustancial o procesal de la sentencia de segunda instancia, así sea advertido al desatar el recurso de casación ${ }^{16}$.

15 En la actualidad un sector de la doctrina especializada discute esta naturaleza o dogma de la casación, al respecto puede consultarse el texto El principio dispositivo de la casación (Bonett Ortíz, 2013).

16 Este análisis se extrae de las motivaciones expuestas por la Corte Suprema de Justicia en los casos (Sentencia CAS-SL 12346, 1999), (Sentencia CAS-SL 14003, 2000) y (Sentencia CAS-SL 25013, 2005). 
Esta limitación de competencia o bajo esta justificación en la que básicamente se indica que la casación no es una instancia más, trae consigo elementos que restringen a su vez la construcción de línea jurisprudencial dada la forma como puede estructurarse la sentencia CAS por el magistrado ponente o los magistrados que en ese momento histórico componen la Sala. Lo anterior por cuanto, por regla general, en la sentencia CAS: 1) es limitado o inexistente el detalle del trámite surtido en las instancias, 2) es limitado o insuficiente el detalle respecto a los hechos y su prueba en las instancias, 3) es limitado o insuficiente el detalle sobre el derecho utilizado, las interpretaciones que se consideraron y la que finalmente se eligió y aplicó en las instancias, 4) en atención a que, más allá del acierto o desacierto de la tesis acogida por la sentencia de segunda instancia está la «técnica de casación», es difícil en muchos casos determinar si la CSJ acoge o no la misma, haciendo compleja la sistematización de las subreglas respecto a las jerarquías funcionales desde los jueces del circuito, los tribunales y finalmente en sede de la CSJ.

Bajo las anteriores consideraciones, pasan a exponerse y analizarse las subreglas que definen el derecho sustancial y procesal en el asunto propuesto:

\subsubsection{Sobre la vigencia, derogatoria y tránsito de las disposiciones declaradas inexequibles y nulas}

La Ley 6 del año 1992 fue publicada el 30-jun-1992, sin embargo, su vigencia quedó condicionada a que fuera expedida y publicada la disposición reglamentaria, la cual llegó el 31-dic-1992 a través del Decreto 2108. Solo con la expedición de este Decreto adquirió plena aplicabilidad el derecho al reajuste dado que exclusivamente en él se definían a) los porcentajes en que debía hacerse el reajuste dependiendo de la fecha de causación del derecho a la pensión, correspondiente a totales del $28 \%$ y $14 \%$ y b) la gradualidad en que se iba a hacer ese incremento, los cuales se harían en forma parcial a partir del 01 de enero de los años 1993, 1994 y $1995^{17}$.

Solo a partir de este momento, 01-ene-1993, el pensionado habría podido acudir, sin conflicto normativo aparente alguno, ante la AP en ejercicio del

17 El año de causación de la pensión en una primera hipótesis regula los casos en el que la pensión ha sido reconocida con anterioridad y hasta el 31-dic-1981, evento en el cual el reajuste total es del $28 \%$, los cuales se pagarían a partir de enero de los años 1993, 1994 y 1995 en porcentajes del 12\%,12\% y 4\%, correspondientemente. En una segunda hipótesis se regulan los casos en el que la pensión ha sido reconocida entre el 01-ene1982 y hasta el 31-dic-1988, evento en el cual el reajuste total es del 14\%, los cuales se pagarían a partir de enero de los años 1993 y 1994 en porcentajes del 7\% y 7\%, correspondientemente. 
derecho de petición en interés particular pretendiendo el ajuste o reajuste. Esta situación de inexistencia de conflicto normativo aparente se comprendería entre el 01-ene-1993 y el 20-nov-1995. Habría de suponerse que una gran cantidad de asuntos fueron resueltos en sede administrativa y hasta judicial en este periodo.

A partir del 20-nov-1995, surge un conflicto normativo que se hace cierto dada la expedición y publicación por la CC de la providencia (Sentencia C-531, 1995) en la cual se hizo la declaratoria formal de INEXEQUIBILIDAD del artículo 116 (Ley 6, 1992), la cual fue ratificada el 18-ene-1996 (Sentencia C-009, 1996), al declararse estarse a lo resuelto en fallo anterior.

A esta época para el pensionado y la AP los cuestionamientos son plurales: ¿qué ocurre o cómo deben decidirse las actuaciones iniciadas con anterioridad e inclusive al 20-nov-1995?, ¿qué ocurre o cómo deben decidirse las actuaciones iniciadas con posterioridad e inclusive el 20-nov-1995?, ¿ es exigible el derecho al ajuste si la actuación administrativa fue iniciada el 21-nov-1995?, ¿solo es exigible el derecho al ajuste si la actuación administrativa fue iniciada hasta el 20-nov-1995?, ¿está vigente el decreto reglamentario y es aplicable el ajuste con fundamento exclusivamente en él?

Este conflicto normativo se agudiza para el pensionado y la AP el 11-jun1998, fecha de expedición y publicación por el CE de la providencia (Sentencia NPI 11636, 1998) en la cual se hizo la declaratoria formal de nulidad del artículo 1. ${ }^{\circ}$ del Decreto 2108 de 1992; así mismo, el 15-abr-1999, al ser expedido y publicado por el CE el fallo (Sentencia NPI 0038-(479)/98, 1999) en el cual se hizo la declaratoria formal de nulidad de los artículos $2 .^{\circ}, 3 .^{\circ}$ y $4 .^{\circ}$ del Decreto 2108 de 1992.

A esta época para el pensionado y la AP los cuestionamientos se incrementan: ¿qué ocurre o cómo deben decidirse las actuaciones iniciadas con anterioridad e inclusive al 11-jun-1998?, ¿qué ocurre o cómo deben decidirse las actuaciones iniciadas con posterioridad al 11-jun-1998?, ¿ es exigible el derecho al ajuste si la actuación administrativa fue iniciada el 12-jun-1998?, ¿solo es exigible el derecho al ajuste si la actuación administrativa fue iniciada hasta el 11-jun-1998?, ¿ antes de que fuera expedida la sentencia del 15-abr-1995, donde fueron declarados nulos los artículos $2 .^{\circ}, 3 .^{\circ}$ y $4 .^{\circ}$, era posible dar aplicabilidad al ajuste?, ¿al haberse declarado inexequible el artículo 116 de la Ley 6 de 1992, automáticamente y sin declaración judicial alguna es inconstitucional e inaplicable la disposición reglamentaria, Decreto 2108 de 1992?, ¿al no haber sido declarado nulo por inconstitucional el Decreto 2108 de 1992 el ajuste era aplicable? 
Y finalmente, a esta gama de problemas ${ }^{18}$ propios a la vigencia, derogatoria y tránsito de disposiciones normativas, puede adicionarse los siguientes: ¿es posible la aplicación de una disposición que ha sido declarada inexequible por la CC?, ¿es posible la aplicación de una disposición que ha sido declarada materialmente nula por inconstitucional por el CE?, ¿Sería posible aplicar el ajuste pensional cuando la disposición que creó el derecho fue declarada inexequible por la CC y la disposición reglamentaria fue declarada nula por inconstitucional por el CE?

Como se observa en la gráfica 1, durante los años 1992, 1993, 1994, 1995 y 1996 no fue proferida ninguna sentencia tipo CAS-SL por la CSJ. Solo hasta el año 1997 se emiten las primeras providencias y hasta la última de ellas en el año 2019 , la cuestión sobre la vigencia, derogatoria y tránsito de las disposiciones normativas, es una de las consideraciones que es continua y problémica al plantearse y decidirse el litigio en sede administrativa y judicial. Una vez analizado el nicho citacional y sistematizado el problema jurídico que resulta suficiente sobre el punto, la caracterización y consecuentemente la creación de la subregla se definiría de la siguiente forma:

\begin{tabular}{|c|c|c|}
\hline \multirow[b]{2}{*}{$\begin{array}{l}\bullet \\
\text { El ajuste se aplica } \\
\text { exclusivamente a } \\
\text { aquellos } \\
\text { pensionados que lo } \\
\text { solicitaron hasta el } \\
\text { 20-nov-1995. }\end{array}$} & La providencia no plantea ni motiva el problema jurídico. & \\
\hline & $\begin{array}{l}\text { 9286, del 18-abr-1997 (M. P. Méndez Arango) } \\
9647 \text {, del 24-jul-1997 (M. P. Méndez Arango) } \\
9820 \text {, del 06-ago-1997 (M. P. Méndez Arango) }\end{array}$ & $\begin{array}{r}\text { a aquellos } \\
\text { pensionados que } \\
\text { lo solicitaron } \\
\text { inclusive con } \\
\text { posterioridad al } \\
\text { 20-nov-1995. } \\
\text { La declaratoria de } \\
\text { inexequibilidad } \\
\text { es irrelevante, y } \\
\text { por esto la AP no } \\
\text { queda eximida de } \\
\text { reconocer y } \\
\text { cancelar el } \\
\text { reajuste } \\
\text { pensional. }\end{array}$ \\
\hline
\end{tabular}

18 La identificación de esta extensa formulación de problemas jurídicos solo es posible en la medida en que se ha buscado, identificado, analizado, examinado, sistematizado y caracterizado toda la jurisprudencia aplicable al asunto, preferentemente a través de la utilización de la ficha de análisis jurisprudencial. Este marco teórico no es posible leyendo «la última sentencia» en el asunto, dado que lo más probable es que el derecho sustancial y/o procesal del asunto no se encuentre allí, o en cualquiera otra providencia individualmente considerada. 


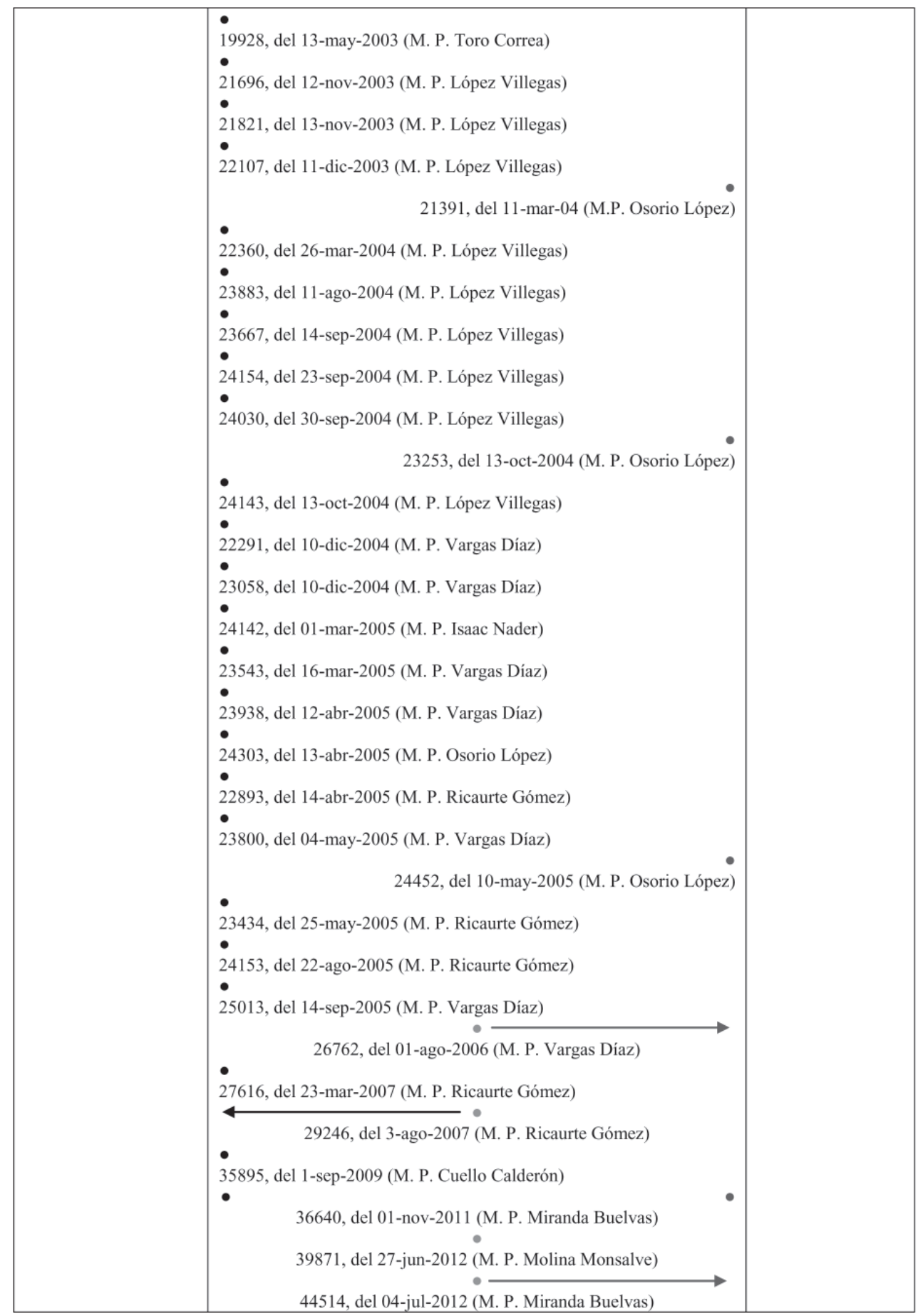




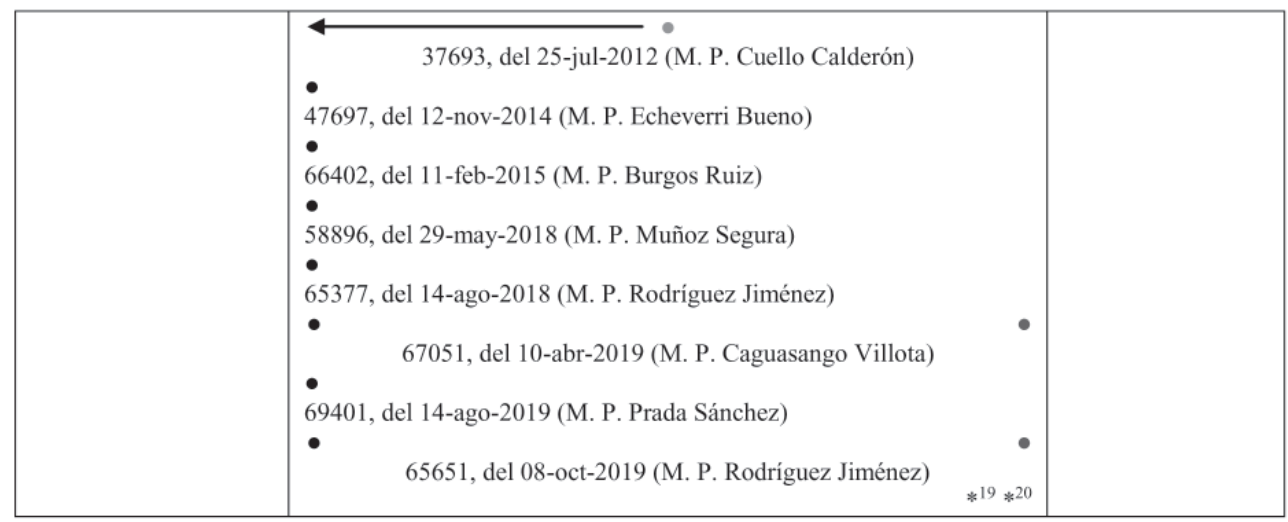

Cuadro 4. Línea jurisprudencial de problema jurídico procesal sobre la vigencia, la derogatoria y el tránsito de las disposiciones declaradas inexequibles y nulas.

Fuente: Elaboración propia del autor.

19 La flecha orientada hacia alguno de los extremos indica que, aunque en esa específica providencia no se hizo motivación expresa frente a acoger una u otra opción, dadas las motivaciones expuestas por las instancias y los argumentos del casacionista que se hacen explícitas en la sentencia CAS, podría afirmarse que la postura se inclina hacia ese extremo fijado.

20 Teniendo en cuenta este problema jurídico, las fechas en las que fueron presentadas las correspondientes peticiones por los pensionados, en los casos en los que la información se registra en el texto de la sentencia, fueron las siguientes:

\begin{tabular}{|l|l|l|}
\hline Expediente & Entidad demandada & $\begin{array}{l}\text { Presentación } \\
\text { de la petición }\end{array}$ \\
\hline 23938 & Departamento del Valle del Cauca & 20 -nov-2001 \\
\hline 22893 & $\begin{array}{l}\text { Instituto de Financiamiento, Promoción y Desarrollo de Manizales, } \\
\text { INFIMANIZALES }\end{array}$ & 28 -jul-2000 \\
\hline 27616 & Departamento del Valle del Cauca & 21 -nov-2001 \\
\hline 29246 & $\begin{array}{l}\text { Departamento de Antioquia } \\
\text { Caja Nacional de Previsión Social, CAJANAL }\end{array}$ & 07 -mar-2002 \\
\hline 58896 & $\begin{array}{l}\text { Distrito Especial Industrial y Portuario de Barranquilla, Secretaría de } \\
\text { Hacienda Distrital, Fondo de Pensiones Territoriales del Distrito de } \\
\text { Barranquilla }\end{array}$ & 17 -sep-2001 \\
\hline 67051 & Empresas Municipales de Cali, EMCALI-EICE E. S. P. & 09 -nov-2006 \\
\hline 65651 & Empresas Municipales de Cali, EMCALI-EICE E. S. P. & 18 -jun-2010 \\
\hline
\end{tabular}

En todos los demás casos la Corte no ofrece esta información. Naturalmente, el reconocimiento del derecho a la pensión en todos los casos fue en una fecha anterior y hasta el 31-dic-1988, no siendo posible que se pretendiera el ajuste a partir de la fecha de reconocimiento, dado que el mismo solo se haría efectivo a partir y de forma progresiva desde el año 1993 hasta 1995; ese es el sentido del artículo 4. (Decreto 2108, 1992) al disponer que «Los reajustes ordenados en el presente decreto comenzarán a regir a partir de las fechas establecidas en el artículo $10^{\circ}$ y no producirán efectos retroactivos». 
Como se observa, las dos opciones hermenéuticas más relevantes - anotadas al lado derecho e izquierdo de la tabla - , derivadas de las eventuales respuestas a la gama de problemas que se plantearon, son abiertamente contrarias y en torno a su aplicabilidad la TENDENCIA se orienta a la subregla definida en el margen izquierdo, por lo que se le dan plenos efectos a lo que tradicionalmente se enseña y entiende sobre los efectos de la inexequibilidad; por otro lado, y en lo que denominaremos son QUIEBRES A LA TENDENCIA, se podría afirmar que se reconoce la aplicabilidad a pesar de que la disposición que crea el derecho desde la Ley fue declarada INEXEQUIBLE y poco después la disposición reglamentaria fue declarada NULA, razonamiento peculiar sobre el que, en un momento dado tanto en sede administrativa como judicial, se centró la discusión, dados los efectos de las disposiciones a partir del 20-nov1995, fecha en que es expedida y publicada la sentencia C-531-1995.

El punto sobre los efectos del fallo C-531-1995 es tan neurálgico que en su momento originó que en sede de casación el magistrado ponente de una de las sentencias CAS presentara aclaración de voto sobre su propia providencia, dado que en su criterio i) la decisión de la CC de resolver que se debía seguir aplicando una disposición declarada inexequible fue hecha sin tener facultad para ello, ii) carece por completo de valor vinculante para un juez que con sujeción a la $\mathrm{CP}$, las leyes que regulan la materia y el significado de la expresión inexequible, comprende «que no se puede hacer, conseguir o llevar a efecto» por ser inconstitucional, con lo cual es «manifiesto lo absurdo de una sentencia que al propio tiempo que declara inexequible un precepto legal autoriza que se continúe aplicando dicha disposición con posterioridad al fallo»; en este mismo sentido, adiciona que iii) aplicar una disposición que es contraria a la CP implica un franco desconocimiento del orden constitucional y de su jerarquía normativa superior $\mathrm{y}$, iv) no es viable invocar un derecho adquirido con fundamento en una norma que es inconstitucional, por cuanto no se tendría un justo título (ACLA Sentencia CAS-SL 9820, 1997).

Entonces solo aquellos pensionados que presentaron sus derechos de petición hasta el 20-nov-1995 tendrían derecho al reconocimiento del ajuste o solo aquellos a los cuales les fue emitido acto administrativo de reconocimiento a esa fecha tendrían derecho, y aquellos que se encontraban en trámite deberían ser desestimados. Aunado a ello, se debería entender que a partir del 20-nov-1995 el decreto reglamentario corrió la misma suerte ante la imposibilidad de continuar produciendo efectos jurídicos válidos.

Esta tesis fue acogida por la CSJ en el posterior caso 18189, con lo que se definiría la subregla a partir de la cual al haber sido declarado inexequible el artículo 116 no se permite su legal aplicación; sin embargo, súbitamente y sin ninguna referencia al caso inmediatamente anterior, en la sentencia CAS 18758, 
defiende los efectos definidos por la CC en la sentencia C-531-1995 a la declaratoria de inexequibilidad, los cuales fueron aplicados por el tribunal de instancia, con lo cual se evidencia contundentemente la inexistente disciplina de la CSJ en la sistematización del punto.

Posteriormente, a partir de las transcripciones textuales de párrafos enteros que se hacen en los casos ulteriores, puede afirmarse que la tesis expuesta en el caso 18189 es reiterada en los expedientes 19928, 21696, 21821, 22107, 22360, 23883, 23667, 24154, 24030, 24143, 22291, 23058, 24142, 23543, 23938, 24303, 22893, 23800, 23434, 24153, 25013, 27616, 29246, 35895, 37693, 47697, 66402, 58896,65377 y 69401 , aunque no sea esta la justificación por la cual se niegue la pretensión del demandante, dado que la CSJ en muy pocos casos indica la fecha en la que fue presentado el derecho de petición por los pensionados ante la AP, lo cual impide hacer cualquier afirmación a título de hipótesis o postura implícita en los mismos, para contrastarla teniendo en cuenta la fecha en la que fue expedida la sentencia C-531-1995, el 20-nov-1995.

Solo en los casos 21391, 23253, 24452, 26762 y 44514, se retoma la subregla acogida en el caso 18758, sin hacer ninguna labor de motivación respecto a toda la jurisprudencia dada en el año 2003, en la que se acogió la subregla del caso 18189. Esto evidencia cómo la CSJ toma solo la jurisprudencia pasada que le es útil en un momento determinado, omitiendo referir en forma completa sus decisiones y sistematizar el problema jurídico, lo cual, de conformidad a la imperativa motivación de la providencia judicial, es un deber que tiene aun siendo el juez de más alta jerarquía en la jurisdicción ordinaria, dado que solo así se puede hablar de una providencia legítima (Yañez Meza, 2016).

Aunado a lo anterior, es relevante en este punto lo que acontece en los casos 23253 y 24452, donde se presenta una protuberante contradicción. En la sentencia CAS-SL 24452, al igual que en la 23253, se cita y fundamenta para decidir, lo dispuesto en el caso 21821, que a su vez se fundamentó en el asunto 19928, el cual refiere el expediente 18189. En este último caso, la tesis que se adopta por la CSJ es aquella a partir de la cual al haber sido declarada la Ley inexequible, ello no permite su legal aplicación, y esto hace parte de la transcripción que la CSJ hace en la sentencia 24452, yéndose hasta el origen, de un segmento de la sentencia 18189. Sin embargo, la CSJ en estos casos luego de esta transcripción de las motivaciones del caso pasado, formula en ese expediente presente argumentos que se encaminan a la antítesis, dado que afirma que la declaración de inconstitucionalidad no impide que los reajustes pensionales sean exigibles. Todo lo cual ratifica más allá de las recurrentes omisiones de la CSJ, el caos (Taruffo, 2014) que con ello se genera tanto para el pensionado que exigirá su derecho, como para la $\mathrm{AP}$ que es competente para su reconocimiento y pago. 
Ahora, esta situación se acentúa en el caso 36640, donde la CSJ en sus transcripciones textuales toma la tesis sobre el punto que se define desde el caso 18189 y a su vez la de la sentencia 23253, por lo que se encuentra una sentencia que asume dos tesis que son entre sí contradictorias, lo cual se reproduce en los casos 67051 y 65651 del año 2019. Finalmente, se observa cómo la CSJ para los casos 29246, 39871 y 37693 omite cualquier referencia a toda su jurisprudencia pasada dejando inmotivado el punto.

En algunos de los casos expuestos en el cuadro 4 se observa que, aunque en la específica sentencia CAS-SL no se motiva ni plantea el problema jurídico, se hace una flecha hacia alguno de los extremos, lo cual significa que al hacerse un análisis sistémico de todas las partes en las que se configura la sentencia, puede inferirse que se inclina a una de las opciones determinadas, pero no porque plantee y esquematice, desarrolle y concluya el punto. Esta es una circunstancia que no debería presentarse y que sustenta aún más la afirmación acerca del caos en que se encuentra una seria sistematización del problema jurídico que se aborda. No es adecuado y puede haber un alto riesgo en hacerle decir a la providencia lo que no dice, al dejarle a la subjetividad del litigante o el investigador y de cara al principio de previsibilidad del derecho esta inclinación, por lo que la completud del asunto debe ser plena al momento de emitirse sentencia.

\subsubsection{Sobre la exclusión en la aplicación del ajuste a los pensionados del orden territorial y la exclusividad del derecho a los pensiona- dos del orden nacional}

La jurisdicción ordinaria laboral teniendo en cuenta toda su estructura, en ningún tiempo ha sido completamente unísona respecto a la exclusiva aplicabilidad del ajuste a pensionados del orden nacional o sobre la exclusión radical de los pensionados del orden territorial, bien se trate de órganos distritales, departamentales o municipales. En las instancias algunas decisiones de los Juzgados en la visión histórica de esta línea ordenaron el ajuste, aunque se tratara de órganos del orden territorial, al igual que algunos Tribunales en segunda instancia que revocaron y declararon el derecho al reajuste, luego no fue uniforme en las instancias el punto, aunque mayoritariamente se hayan inclinado por la exclusión de los pensionados del orden territorial. Con esto, en sede de CSJ, la posición ha sido uniforme a lo largo de estos más de 23 años al imponer que el ajuste aplica exclusivamente a pensionados del orden nacional.

Como se observa en la gráfica 1, en color rojo se ilustran los casos en que se trataba de órganos del orden nacional, en color azul en el evento en que se demandó a órganos del orden territorial y aunque se pudiera pensar que no fuese posible, en color verde se ilustra el caso en el que fue demandada una empresa privada. En todo este tiempo la exclusión en la aplicación del ajuste 
a los pensionados del orden territorial y la exclusividad del derecho a los pensionados del orden nacional es otra de las consideraciones que es continua y problémica al plantearse y decidirse el litigio en sede administrativa y judicial. Una vez analizado el nicho citacional y sistematizado el problema jurídico que resulta suficiente sobre el punto, la caracterización y consecuentemente la creación de la subregla se definiría de la siguiente forma:

¿El derecho al ajuste o reajuste pensional creado en la Ley 6 y reglamentado por el Decreto 2108 del año 1992 aplica a los pensionados del orden nacional exclusivamente o puede extenderse sus efectos a pensionados del orden territorial?

\begin{tabular}{|c|c|c|}
\hline \multirow[b]{2}{*}{$\begin{array}{l}\text { El ajuste se aplica } \\
\text { exclusivamente a } \\
\text { pensionados del } \\
\text { orden nacional. }\end{array}$} & La providencia no plantea ni motiva el problema jurídico. & \\
\hline & 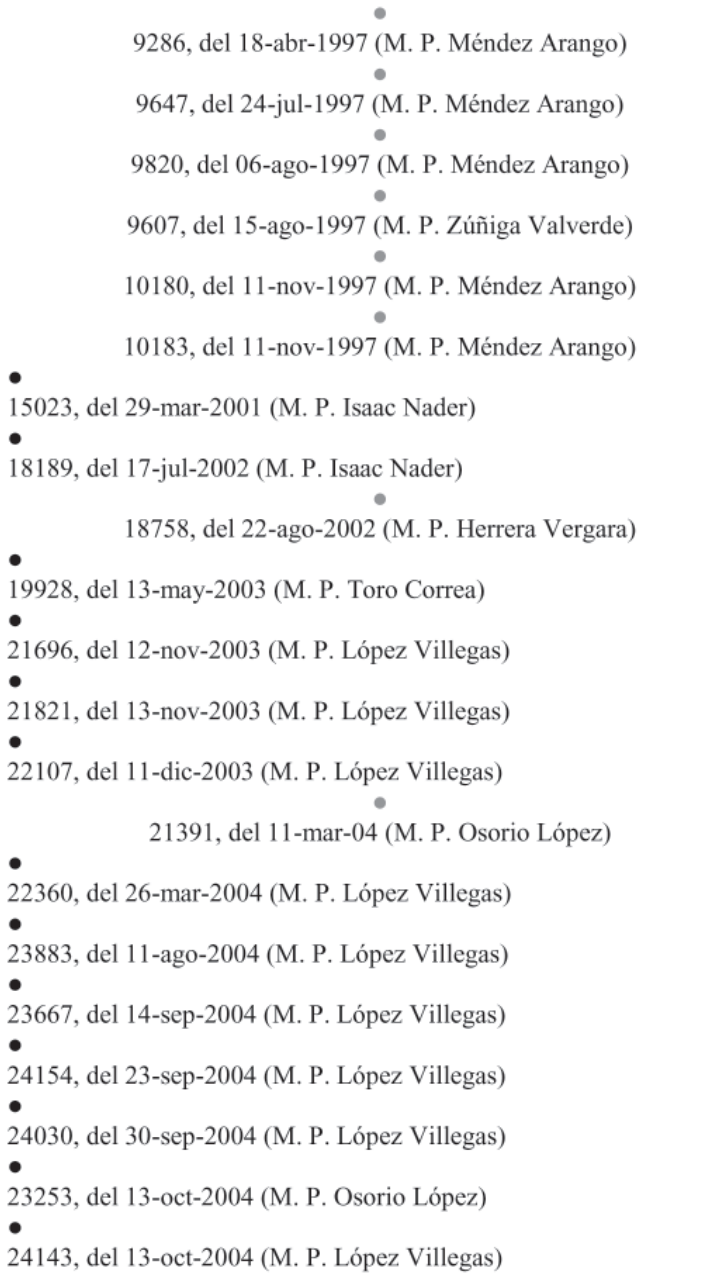 & $\begin{array}{c}\text { El ajuste se aplica } \\
\text { extensivamente a } \\
\text { pensionados del } \\
\text { orden territorial. }\end{array}$ \\
\hline
\end{tabular}




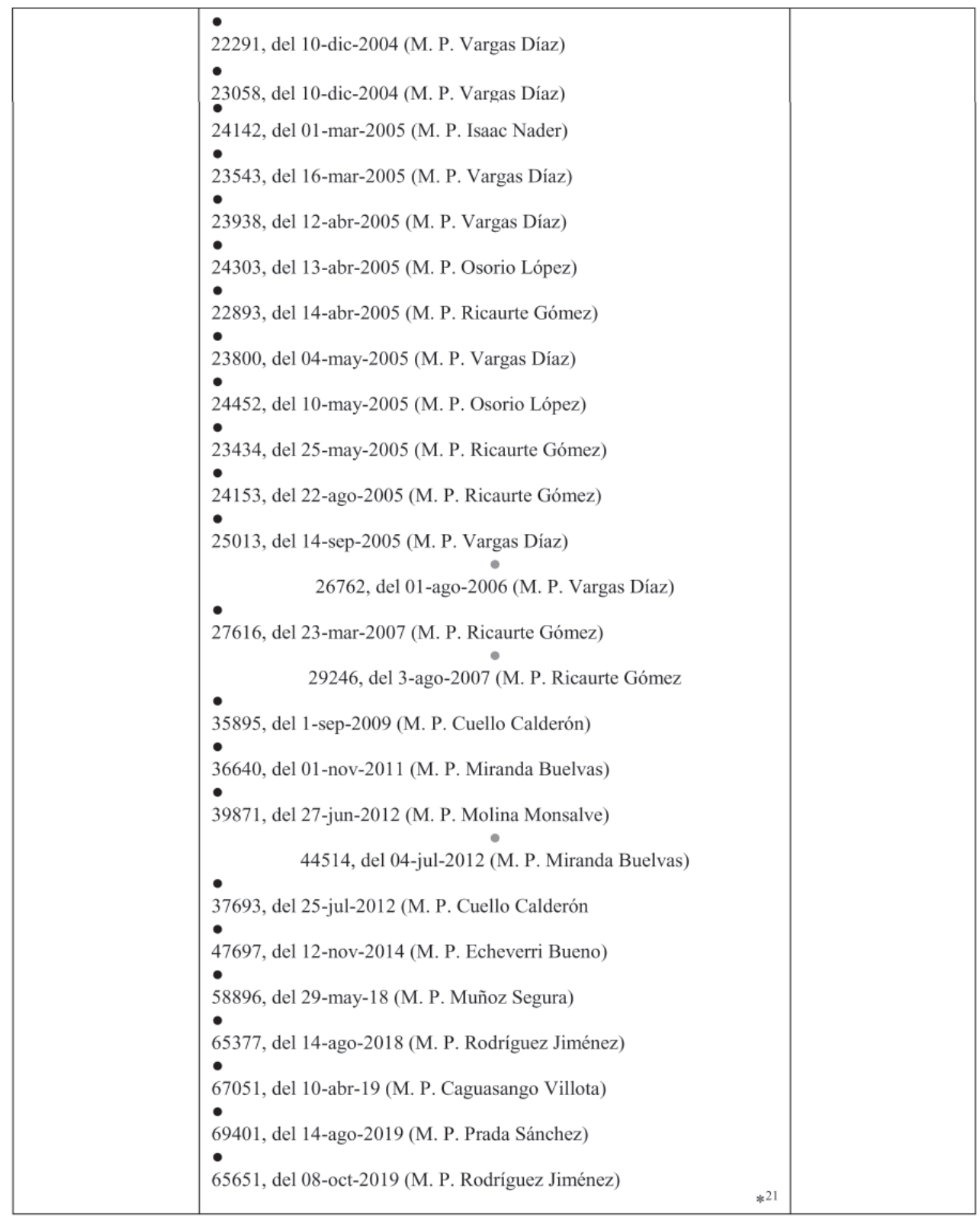

Cuadro 5. Línea jurisprudencial de problema jurídico sustancial sobre la exclusión en la aplicación del ajuste a los pensionados del orden territorial y la exclusividad del derecho a los pensionados del orden nacional. Fuente: Elaboración propia del autor.

21 De igual forma se presenta la relación de autos a través de los cuales se inadmitió el recurso de casación, principalmente por razón del interés para recurrir. Estos son vs. 
La discusión en este punto parte de establecer si, por un lado, el órgano del cual se era pensionado fue del sector público nacional o, por el contrario, era del sector público territorial - orden distrital, departamental o municipal - y, por otro lado, si la disposición del artículo 116 de la Ley 6 de 1992 era aplicable solo a los pensionados del sector público nacional o era extensiva a los pensionados del sector público territorial, por lo que podría considerarse que el demandante debía demostrar la naturaleza del órgano, nacional o territorial.

Como se observa en el cuadro 5, solo hasta el año 2001, a través del caso 15023, la CSJ crea la subregla a partir de la cual el ajuste solo es aplicable a pensionados del sector público nacional, siendo esta inexistente en todos los juicios anteriores, aunque pueda considerarse justificable en la medida de que en todos estos actuaban como demandados órganos del orden nacional. Esta postura se consolida con mayor claridad en el caso 18189 donde, frente a la clara pertenencia al orden territorial del órgano demandado, la CSJ dispone que la aplicabilidad de los preceptos de la Ley 6 y el Decreto 2108 de 1992 se predica únicamente respecto de pensiones del orden nacional, descartando su extensión a pensionados del orden territorial.

La imposibilidad de esta extensión la justifica la CSJ en el caso 19928 a partir de que 1) de hacerse se desbordaría el querer del legislador, 2) el tenor de la Ley es claro, no siéndole dable al intérprete darle alcances distintos o hacerle producir efectos en ámbitos diferentes, y 3) no existe un derecho adquirido en los pensionados del sector público territorial en la medida en que aún antes de la declaratoria de inexequibilidad la disposición limita a los destinatarios del ajuste al sector público nacional ${ }^{22}$.

Esta subregla es acogida posteriormente en forma clara desde las sentencias CAS 21696, 21821, 22107, 22360, 23883, 23667, 24154, 24030, 23253, 24143, 22291,

Fondo de Ahorro y Vivienda Distrital, FAVIDI (Auto 21695, 2003); vs. Fondo de Ahorro y Vivienda Distrital, FAVIDI (Auto 22431, 2003); vs. Fondo de Ahorro y Vivienda Distrital, FAVIDI (Auto 22648, 2003); Instituto de Financiamiento, Promoción y Desarrollo de Manizales, INFIMANIZALES (Auto 23019, 2003); vs. Empresa de Energía de Bogotá S. A., E. S. P. (Auto 23040, 2003); vs. Fondo de Ahorro y Vivienda Distrital, FAVIDI (Auto 23269, 2004); vs. Fondo de Ahorro y Vivienda Distrital, FAVIDI (Auto 23337, 2004); vs. Fondo de Ahorro y Vivienda Distrital, FAVIDI (Auto 22287, 2003). Sobre estas decisiones resulta particular que haya sido el interés para recurrir la razón por la cual se inadmite la demanda de casación, cuando casi en la totalidad de los casos que se muestran en la línea se trataba de situaciones de un pensionado; luego, en todos estos no habría interés para recurrir, por lo que cabe cuestionarse: ¿Cuál fue el criterio para la admisión de unos casos y la inadmisión de otros, dada la identidad en la naturaleza del asunto y su cercana equivalencia en cuanto al interés para recurrir?

22 En los casos donde el órgano demandado era del orden nacional, esto es 18758, 21391, 26762 y 44514, la CSJ no desarrolló este punto. 
$23058,24142,23543,23938,24303,22893,23800,24452,23434,24153,25013$, $27616,35895,36640,39871^{23}, 37693,47697,58896,65377,67051,69401$ y 65651 , sin ninguna justificación adicional. Sobre este punto resulta relevante lo acontecido en el expediente 29246, en el que no se trató este punto para negar la pretensión, contrario a como ocurrió regularmente en todos los casos donde el demandado fue un órgano territorial.

\subsubsection{Sobre la calidad de los destinatarios del ajuste pensional: la condición de trabajador oficial o empleado público}

Como se observa en la gráfica 1, la calidad de los destinatarios del ajuste pensional, a partir de la condición de trabajador oficial o empleado público, cuya vinculación se da a través de acto administrativo, es otra de las consideraciones que, aunque no es continua y central al plantearse y decidirse el litigio en sede administrativa y judicial, tiene una relevancia significativa. A este respecto, la calidad del sujeto define la jurisdicción y el juez que conocerá el litigio. Si el pensionado tuvo la condición de empleado público, el asunto lo conocerá la Jurisdicción de lo Contencioso Administrativo con el juez contencioso administrativo ${ }^{24}$; si el pensionado fue un trabajador oficial, el asunto lo conocería la Jurisdicción Ordinaria con el juez laboral. Una vez analizado el nicho citacional y sistematizado el problema jurídico que resulta suficiente sobre el punto, la caracterización y consecuentemente la creación de la subregla se definiría de la siguiente forma:

¿El derecho al ajuste o reajuste pensional creado en la Ley 6 y reglamentado por el Decreto 2108 del año 1992 aplica a los pensionados que ostentaron la condición de trabajadores oficiales?

\begin{tabular}{|c|c|}
\hline & La providencia no plantea ni motiva el problema jurídico. \\
\hline & $\begin{array}{l}\bullet \\
\text { 9286, del 18-abr-1997 (M. P. Méndez Arango) } \\
\bullet \\
\text { 9647, del 24-jul-1997 (M. P. Méndez Arango) } \\
\bullet \\
\text { 9820, del 06-ago-1997 (M. P. Méndez Arango) } \\
\bullet \\
\text { 9607, del 15-ago-1997 (M. P. Zúñiga Valverde) }\end{array}$ \\
\hline
\end{tabular}

23 Debe indicarse que en este caso 39871, aunque la CSJ no cita ninguna de sus providencias pasadas sí hace una breve motivación acorde a la tesis expuesta en la sentencia 19928.

24 De conformidad a la actual y vigente disposición del artículo 105 del CPACA (Ley 1437, 2011), la jurisdicción de lo contencioso administrativo no conocerá de los siguientes asuntos -Excepciones - : «...4. Los conflictos de carácter laboral surgidos entre las entidades públicas y sus trabajadores oficiales». 


\begin{tabular}{|c|c|c|}
\hline $\begin{array}{l}\bullet \\
\text { A los } \\
\text { pensionados } \\
\text { como } \\
\text { trabajadores } \\
\text { oficiales NO les } \\
\text { aplica el ajuste } \\
\text { del artículo } 116 \\
\text { de la Ley } 6 \text { de } \\
\text { 1992. }\end{array}$ & 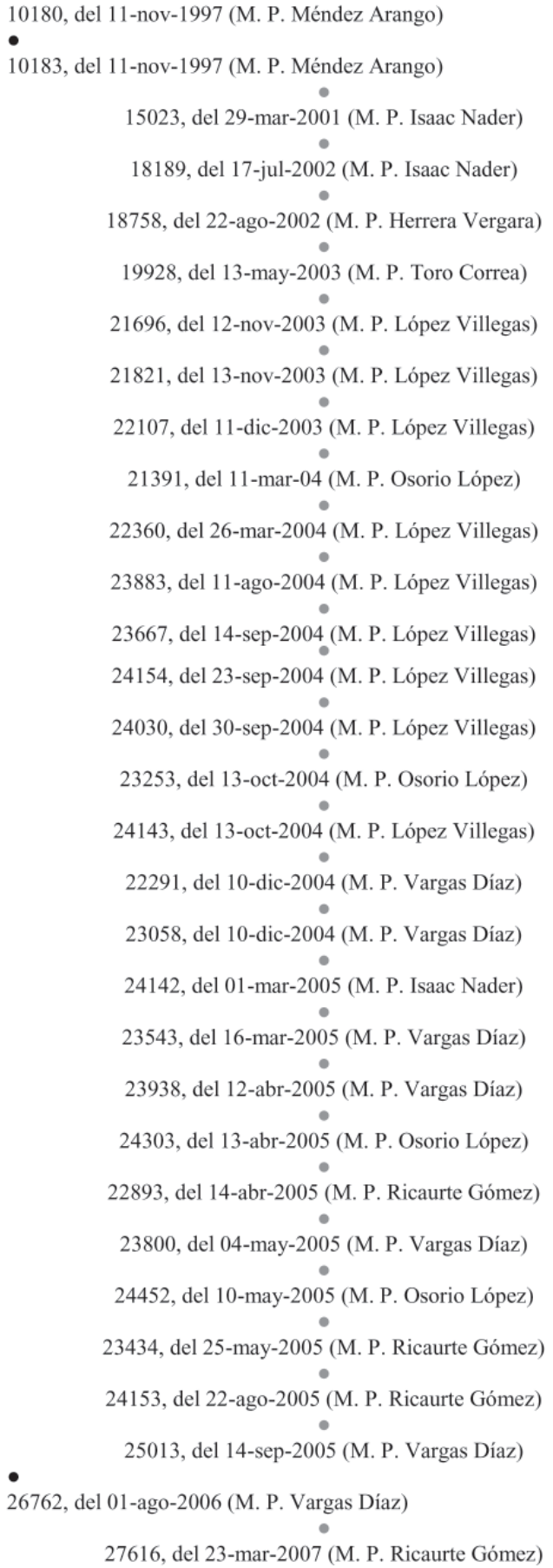 & $\begin{array}{r}\text { A los } \\
\text { pensionados } \\
\text { como } \\
\text { trabajadores } \\
\text { oficiales SÍ les } \\
\text { aplica el ajuste } \\
\text { del artículo } 116 \\
\text { de la Ley } 6 \text { de } \\
1992 .\end{array}$ \\
\hline
\end{tabular}




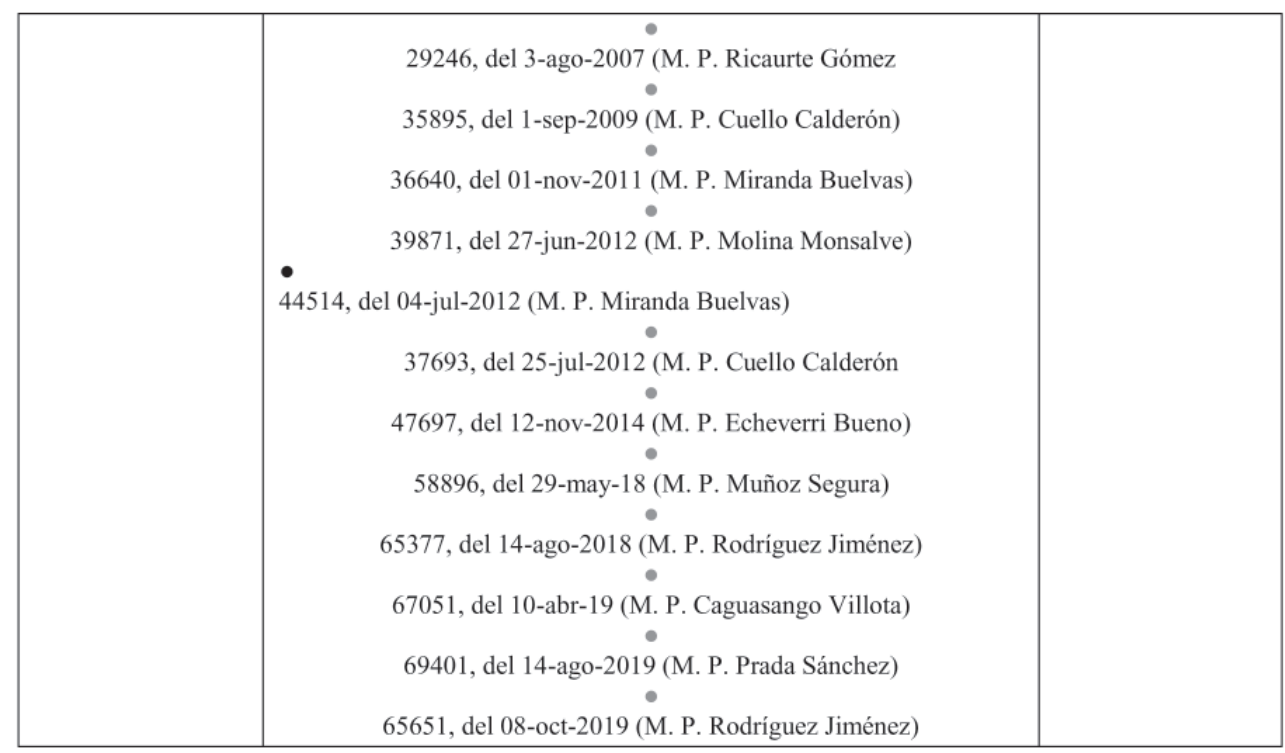

Cuadro 6. Línea jurisprudencial de problema jurídico sustancial sobre la calidad de los destinatarios del ajuste pensional: la condición de trabajador oficial o empleado público. Fuente: Elaboración propia del autor.

Como se observa en gran parte de la línea el problema jurídico ni siquiera se plantea por la CSJ, esto debido a que la subregla que tiene mayor injerencia en la prosperidad o no de la pretensión es la analizada en el punto 2.1.2. Solo en los casos en los que quien era demandado fue un órgano del orden nacional, la CSJ abordó el punto inclinándose hacia la opción hermenéutica a partir de la cual a los pensionados como trabajadores oficiales NO les aplica el ajuste del artículo 116 de la Ley 6 de 1992.

De tal forma que, en este punto, lo primero es determinar el régimen jurídico que ostenta el pensionado a partir de la condición que se tuvo. Por ejemplo, en los casos en los que el demandado fue el BANCO DE LA REPÚBLICA a partir de la función exclusiva que este órgano cumple, se consideró que este tiene un régimen jurídico único, especial o propio, sobre el cual además algunas relaciones se regulan por el Código Sustantivo del Trabajo - en adelante CST - y otras por las aplicables a los empleados públicos, como es el caso de quienes integran la Junta Directiva. En los casos en que aquellos pensionados pretendieron el ajuste de la Ley 6 de 1992 en su artículo 116, la calidad de trabajadores oficiales a quienes les aplica el CST fue determinante para negar el ajuste, por cuanto la disposición nunca les fue aplicable según la CSJ y, en consecuencia, no podrían obtener beneficios de un régimen jurídico distinto al cual se encuentran sometidos, que es el propio al del sector privado, luego no son relaciones que se rijan por el régimen del sector público, ni es una disposición 
única, especial o propia que le sea aplicable conforme al régimen jurídico del banco a partir de sus estatutos, el reglamento interno de trabajo o las convenciones colectivas que se celebraran.

Otro ejemplo equiparable se encuentra respecto a la EMPRESA COLOMBIANA DE PETROLEOS - ECOPETROL -25 , respecto de quienes a partir de su condición de trabajadores oficiales y a pesar de que la naturaleza jurídica del órgano es la de una empresa industrial y comercial del Estado, su regulación laboral es la del sector privado; en otros términos, se encuentran cobijadas por las normas que reglamentan las relaciones entre trabajadores particulares, concretamente las contenidas en el Código Sustantivo del Trabajo. En consecuencia, según este criterio de la CSJ, el ajuste de Ley 6 no le es aplicable, lo cual se refuerza en el hecho de que aquí también se encuentra un régimen jurídico especial, producto de negociaciones colectivas y otras fuentes.

Esta misma condición de trabajadores oficiales es la que ostentaban los demandantes en la línea jurisprudencial, salvo los casos 18758, 21696, 21821, 22107, 21391, 23883, 23667, 24154, 24030, 23058, 24142, 23543, 23938, 22893, 23800, $23434,24153,29246,35895,36640,47697,58896,65377$ y 65651, en los que la información que ofrecen las sentencias es insuficiente en el punto, lo cual resulta particularmente relevante por cuanto, aunque no hay duda de que el órgano demandado es del orden territorial, no puede conocerse si se trataba sobre la condición de empleados públicos.

De este recorrido es relevante destacar los casos en los que fue demandada la ELECTRIFICADORA DE BOLÍVAR S. A., E. S. P., que es un órgano del orden nacional, siendo estos los únicos casos (2) donde la pretensión del reajuste se otorgó, aunque a causa de las deficiencias en la construcción de la sentencia, no es posible determinar si se trataba de la condición de un trabajador oficial o no, tal como ocurrió en los casos 18758 y 21391.

De esta manera, la configuración de la subregla se identifica desde la omisión en la motivación del punto y hacia la opción hermenéutica a partir de la cual a los pensionados como trabajadores oficiales no les aplica el ajuste pensional, posición que se crea a partir de esos ocho (8) casos, de los cuarenta y ocho (48) analizados.

\subsubsection{La carga de la prueba del desajuste en la pensión: ¿carga estática en el demandante o presunción legal que invierte la carga?}

En todo este tiempo la carga de la prueba en el desajuste de la pensión en el demandante o no, es otra de las consideraciones que es continua y problémica

25 Los casos atinentes a la Empresa Colombiana de Petróleos son 26762 y 44514. 
al plantearse y decidirse el litigio en sede administrativa y judicial. Una vez analizado el nicho citacional y sistematizado el problema jurídico que resulta suficiente sobre el punto, la caracterización y consecuentemente la creación de la subregla se definiría de la siguiente forma:

\begin{tabular}{|c|c|c|}
\hline \multicolumn{3}{|c|}{$\begin{array}{l}\text { ¿El desajuste de la pensión debía ser probado por el demandante en el proceso judicial o la existencia del } \\
\text { desajuste constituye una presunción jurisprudencial? }\end{array}$} \\
\hline $\begin{array}{l}\text { El desajuste debía } \\
\text { ser probado en el } \\
\text { proceso por el } \\
\text { demandante }\end{array}$ & 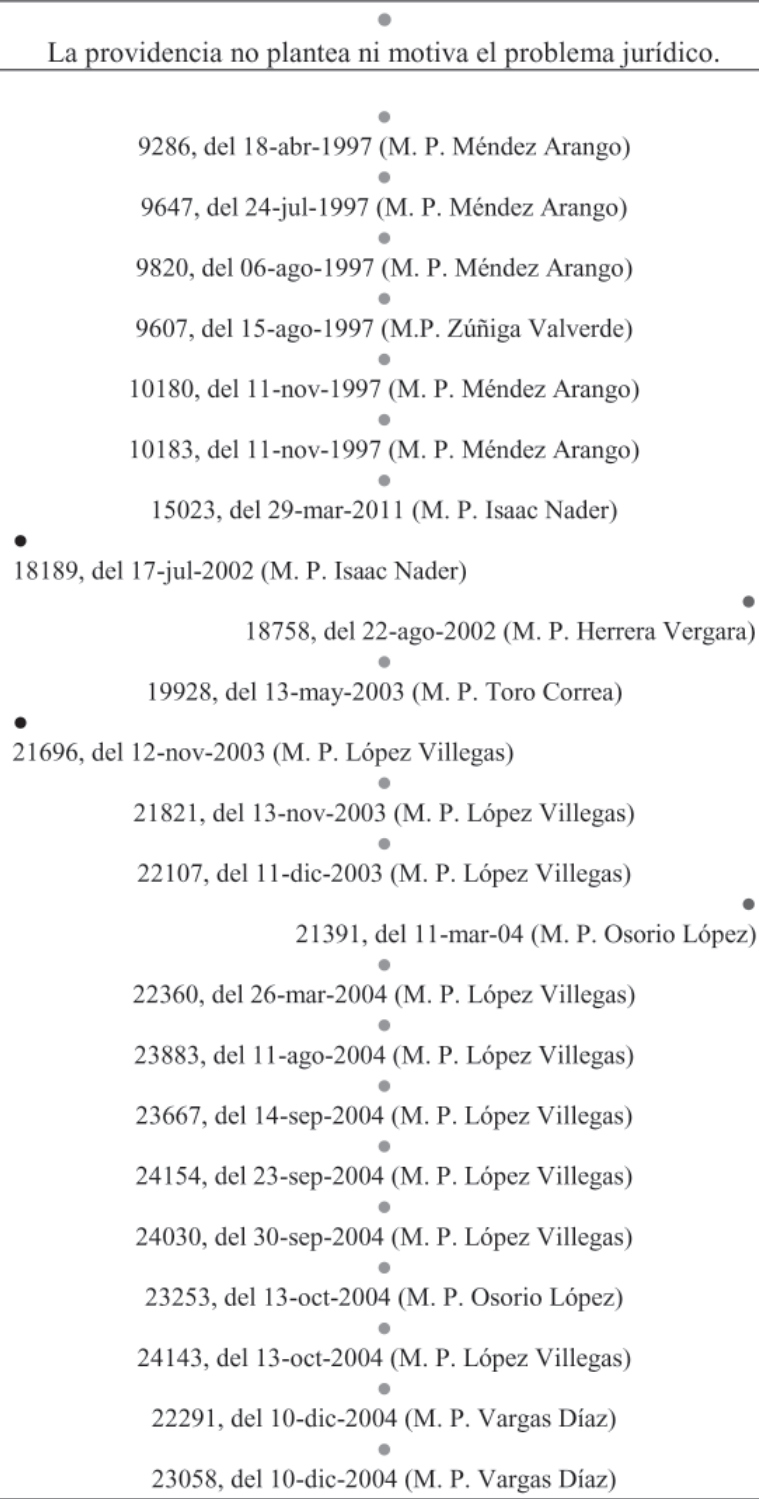 & $\begin{array}{r}\text { El desajuste no } \\
\text { debía ser probado } \\
\text { en el proceso por } \\
\text { el demandante }\end{array}$ \\
\hline
\end{tabular}




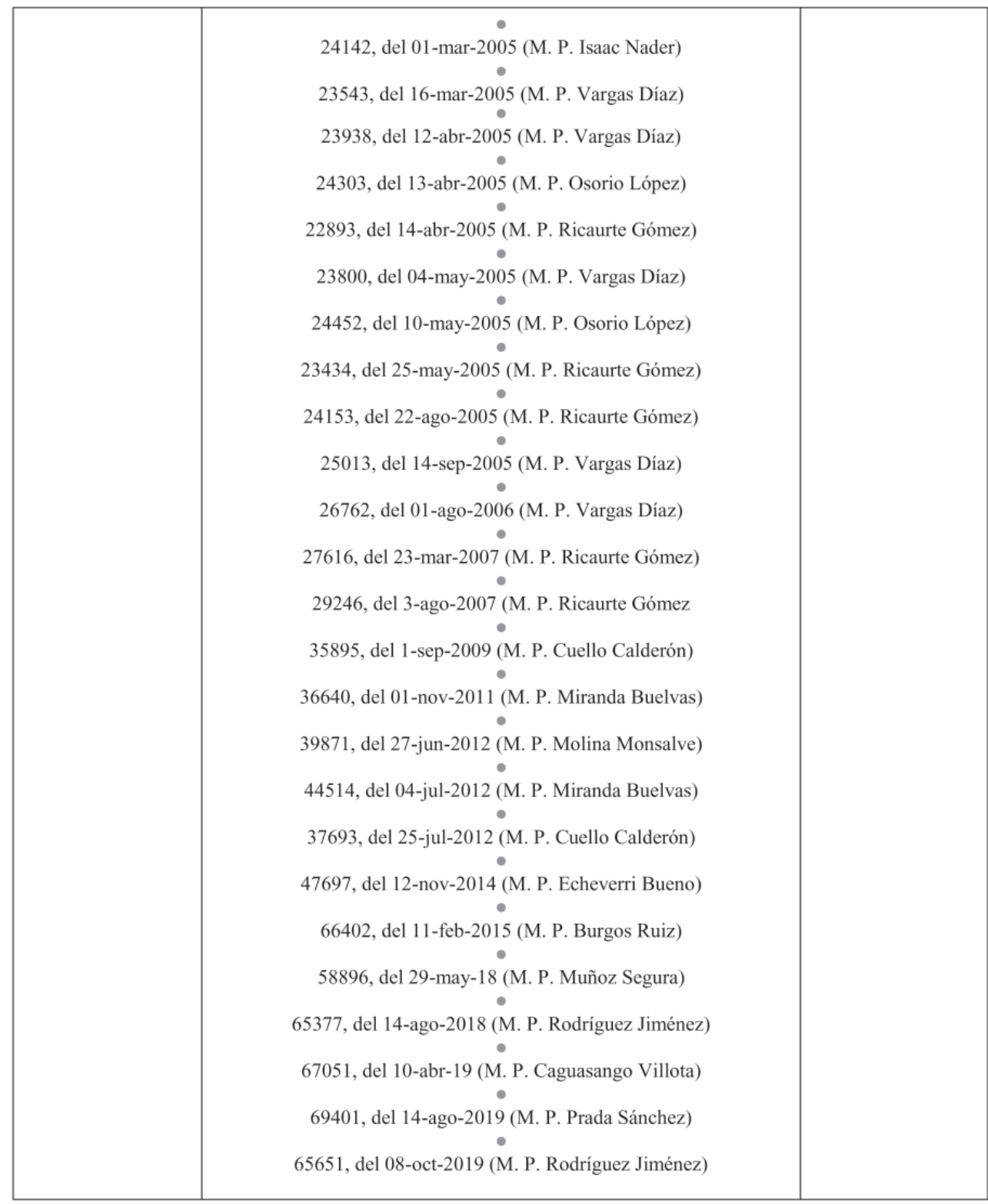

Cuadro 7. Línea jurisprudencial de problema jurídico procesal sobre la carga de la prueba del desajuste en la pensión: ¿carga estática en el demandante o presunción legal que invierte la carga? Fuente: Elaboración propia del autor.

La discusión en este punto parte de establecer si: 1) en los casos concretos debía conocerse por prueba aportada por el pensionado-demandante, cuál 
era la cuantía (s) de la mesada que percibía desde el momento en que se reconoció y liquidó el derecho a la pensión y durante los años siguientes, pasando por 1988 y hasta el mes de diciembre del año 1992 y 2) si el demandante debía demostrar que los aumentos o reajustes hechos a sus mesadas fueron inferiores a los aumentos decretados anualmente por el gobierno nacional a través del salario mínimo mensual legal vigente - en adelante SMMLV - , es decir, si debía probarse la diferencia existente entre el incremento del salario y la pensión.

Como se observa en el cuadro 7, solo hasta el año 2002 a través del caso 18189 la CSJ crea la subregla a partir de la cual el demandante debe probar la existencia de desajuste de su pensión, siendo esta inexistente en todos los juicios anteriores. Para este efecto, se entendería que es imperativo tener ese referente histórico de pagos desde el reconocimiento de la pensión o su erogación efectiva hasta el mes de diciembre del año 1992, con el consecuente análisis contable o financiero que demuestre el desajuste o la diferencia existente; sin embargo, súbitamente y sin ninguna referencia al caso inmediatamente anterior, en la sentencia CAS 18758, dispone que lo que hizo el gobierno nacional fue ordenar un reajuste general automático de las pensiones de jubilación, sin que fuera menester entrar a demostrar en cada caso cuáles eran los salarios pagados por la entidad obligada al reajuste, con lo cual se evidencia contundentemente la inexistente disciplina de la CSJ en la sistematización del punto.

Posteriormente, la atención a lo dicho en las sentencias 18189 y 18758 es fugaz; así desde el expediente 19928 en el que ni siquiera en una línea se trata el punto sobre la carga de la prueba, pasando por los aislados casos 21696 y 21391, este $\mathrm{y}$ aquel en tesis contrarias, donde en el primero se retoma la subregla como consideración fáctica al no aparecer demostrado que los aumentos efectuados a las correspondientes mesadas pensionales hubieren sido inferiores a los incrementos decretados por el gobierno nacional a los salarios, lo cual fundamentó la decisión de no casar la sentencia del tribunal, se pasa a los casos posteriores 21821, 22107, 22360, 23883, 23667, 24154, 24030, 23253, 24143, 22291, 23058, 24142, 23543, 23938, 24303, 22893, 23800, 24452, 23434, 24153, 25013, 26762, 27616, 29246, 35895, 39871, 44514, 37693, 47697, 66402, 58896, 65377, 67051, 69401 y 65651, donde la CSJ simplemente no formula el problema jurídico específico.

Debe destacarse en este nicho de jurisprudencia el caso 26762, donde se hace referencia y transcribe y cita la sentencia CAS-SL 18758 pero en forma gravemente inadecuada respecto a sus consideraciones, esto por cuanto aquí es notorio cómo omite la CSJ la enunciación de la subregla creada en la sentencia 18758 respecto a que el artículo 116, como se indicó arriba, ordenó un reajuste 
general automático, lo que implica como efecto inmediato que no es necesario que el demandante demuestre el desajuste, debiendo la AP simplemente proceder a aplicar la fórmula del decreto reglamentario. Esto, que en consideración de algunos podría tipificarse como una «intencional omisión» o, para otros, una «legítima selección del extracto», es grave frente al derecho al debido proceso, porque dos asuntos equiparables o semejantes o idénticos - es irrelevante el sinónimo - se juzgan con subreglas radicalmente opuestas, como efectivamente ocurrió en estos casos en donde en el primero de ellos se acoge la pretensión y en el segundo se desestima.

\subsubsection{La sistematización en la motivación de las tesis jurisprudenciales: la creación de subreglas en el asunto concreto}

Al realizar y analizar la sistematización de cada una de las consideraciones que explícita o implícitamente lleva a la formulación de problemas jurídicos que posteriormente tienen la virtualidad de crear o configurar subreglas, en el asunto del reajuste pensional del artículo 116 (Ley 6, 1992), los resultados son los siguientes:

$\mathbf{1}^{\circ}$. Ubicados en los primeros seis asuntos que tienen como común denominador el mismo sujeto demandado (expedientes 9286, 9647, 9820, 9607, 10180 y 10183), es inexistente la cita al caso pasado en esa sucesión de sentencias CAS. En otros términos, la CSJ a pesar de literalmente calcar los párrafos que le sirvieron de considerandos en casos pasados, con mínimas consideraciones adicionales entre una y otra, no fundamenta su motivación en el haber decidido con anterioridad un asunto idéntico, parecido, con semejanza fáctica y jurídica o cualquiera sea el sinónimo que se quiera utilizar, para decidir el caso presente.

Esta es la razón por la cual no se muestra en la gráfica 2 conexión alguna entre las providencias, siendo esta una característica que se extiende a los expedientes 15023, 18189 y 18758, donde en ninguno de ellos se mira al caso pasado para fundamentar y motivar con el fin de justificar el sentido de la decisión en el caso presente.

$2^{\circ}$. Cuando la CSJ refiere un caso pasado, lo cual hizo por primera vez en la sentencia CAS-SL 19928 respecto al expediente 18189, tal como se muestra en la gráfica 2, no hace una sistematización completa de las subreglas que ha ido creando a la fecha. En esta ocasión, usa el caso pasado para fundamentar en el asunto presente el punto (1) sobre la vigencia, derogatoria y tránsito de las disposiciones declaradas inexequibles y nulas y (2) sobre la exclusión en la aplicación del ajuste a los pensionados del orden territorial y la exclusividad del derecho a los pensionados del orden nacional, pero deja de lado el punto 
(3) sobre la carga de la prueba del desajuste en la pensión y (4) sobre el punto de la calidad de los destinatarios del ajuste pensional en cuanto a la condición de trabajador oficial o empleado público ${ }^{26}$.

Esto es una tendencia generalizada en la línea; otro ejemplo se encuentra en el caso 21696, donde a pesar de que se abordan los puntos (1), (2) y (3), se omite la consideración (4) ${ }^{27}$. Así mismo, se presentan casos en los que la CSJ omite la consideración de los puntos (2) y (4) ${ }^{28}$. En otra de las hipótesis la CSJ omite las consideraciones (2), (3) y (4) ${ }^{29}$. Bajo otra hipótesis, se presentan casos en los que la CSJ omite el análisis de las subreglas (1), (3) y $(4)^{30}$. Finalmente, se presenta otro caso en el que la CSJ solo aborda el punto $(4)^{31}$.

$3^{\circ}$. El concepto de motivación en la CSJ - y esto se va haciendo evidente en la medida en que se avanza en la lectura y análisis de cada una de las sentencias en orden cronológico - consiste en transcribir casi que totalmente la parte motiva de algunos casos anteriores, y una vez hecho esto, se dice que, por ello, es decir, con fundamento solo en esa reproducción, en el caso presente se desestiman los cargos.

$4^{\circ}$. En algunos de los casos la CSJ no refiere expresamente sus fallos anteriores, tal como ocurrió en el asunto 37693 del año 2012, en el cual podría encontrarse como justificación la expresión «el ad quem se apoyó en jurisprudencia de esta Sala»; sin embargo, se considera que la CSJ no puede mencionar en abstracto sus subreglas anteriores: por el contrario, debe individualizarlas. Si como se ha evidenciado, no existe una adecuada sistematización en las subreglas, menos aún será objetivo un fundamento a partir de expresiones genéricas.

26 Las sentencias CAS-SL que presentan este mismo defecto son las correspondientes a los expedientes 19928, 21821, 22017, 22360, 23883, 23667, 24154, 24030, 23253, 24143, 22291, 23058, 24142, 23543, 23938, 24303, 22893, 23800, 24452, 23434, 24153, 25013, 27616, 35895, $36640,47697,58896,65377,67051,69401,65651$.

27 Las sentencia CAS-SL que presenta este mismo defecto es la correspondiente al expediente21696.

28 Las sentencias CAS-SL que presentan este mismo defecto son las de los expedientes 21391 y 26762.

29 Las sentencias CAS-SL que presentan este mismo defecto son las correspondientes a los expedientes 29246 y 66402.

30 Las sentencias CAS-SL que presentan este mismo defecto son las correspondientes a los expedientes 39871 y 37693.

31 Las sentencias CAS-SL que presentan este mismo defecto corresponden al expediente 44514. 
$5^{\circ}$. En otras decisiones, la individualización de las providencias de los casos anteriores por la CSJ no es exacta, dado que la Corte equivoca la fecha de expedición y publicación de la sentencia anterior, tal como ocurrió en los casos 22291, 23058 y 23434, respecto a la fecha de la sentencia 22360, la cual fue proferida el 26-mar-2004, no el 16-mar-2004.

Frente a todo lo expuesto, ¿realmente existe algún punto de derecho donde exista una tendencia reiterada y pacífica sobre alguna de las opciones hermenéuticas?, ¿cuáles son las subreglas que deben ser aplicadas en el juicio sobre este asunto desde la jurisprudencia de la CSJ?, ¿es posible que, en la realidad cotidiana de los despachos judiciales, se haga una investigación como la que aquí se hace para decidir UNO de los procesos que se tiene a cargo? En nuestro criterio, la aproximación frente a estos y otros problemas que se han ido quedando planteados debe esquematizarse desde un componente metodológico y otro de fondo. Dichos componentes son los siguientes:

\section{CONCLUSIONES}

\section{Conclusiones metodológicas}

Desde la complejidad del sistema de fuentes la construcción de línea jurisprudencial no es automática, la búsqueda de las providencias en los sistemas dispuestos en la web institucional de los órganos judiciales es aún muy deficiente y depende del momento histórico en el que se hace la pesquisa, ya que es probable que un estudio de línea en un momento dado arroje 16 providencias y que uno o más años después se duplique y más, apareciendo providencias porque en su momento no estaban disponibles, por lo que no podría hablarse de negligencia del investigador o del juez o el litigante. No basta entonces la inclusión de variables relevantes para encontrar todos los casos, dado que aún en aplicación de gran diligencia y rigor científico podría no tenerse todo el conjunto de providencias respecto del asunto.

Una vez se tenga la convicción sobre el encuentro de «toda» la jurisprudencia frente al asunto se hace necesario leer inexorablemente el conjunto de sentencias y autos que se encuentren teniendo en cuenta la naturaleza del asunto y construir la red jurisprudencial, reconociendo con cuidado la enunciación de los casos pasados que trae a colación la decisión que en ese momento se lee y analiza. Esto, porque aún con el empleo de bases de datos especializadas como LEX BASE, VLEX, NOTINET, TIRANT ON LINE o ANALÍTICA LÍNEAS JURISPRUDENCIALES LEGIS, entre otras, no se encuentra la totalidad ni con suficiencia toda la jurisprudencia que haya abordado el mismo asunto. 
Construir líneas jurisprudenciales no es comentar tres, o cinco o diez providencias, o cincuenta o más, transcribiendo uno que otro de sus párrafos sin una sistematización. Es probable que el derecho sustancial y procesal jurisprudencial no se encuentre en la última sentencia frente al asunto. Por ello, para demostrar cuál es el derecho sustancial o procesal jurisprudencial en un asunto concreto, se deben traer al análisis o a los FUNDAMENTOS DE DERECHO, tanto los casos que puedan ser favorables como desfavorables, si del punto de vista del litigante se trata, porque solo así se puede evitar inducir al error al juez; y si desde el punto de vista del juez se trata, porque solo así se puede construir una motivación suficiente que garantice el derecho fundamental al debido proceso, y con mayor énfasis del derecho a la igualdad.

Hacer una sentencia de unificación (U) es una labor compleja. Conforme al estudio realizado en el asunto concreto sobre la materia del derecho al reajuste pensional de la Ley 6 de 1992 y su Decreto Reglamentario 2108 de igual anualidad, podría afirmarse con contundencia que ninguna de las 48 sentencias de casación que han sido proferidas por la Corte Suprema de Justicia en su Sala de Casación Laboral cumple con uno de los fines del recurso de casación, tal cual es el de unificar la jurisprudencia nacional, según lo dispone el artículo 333 del CGP. La motivación de una tipología de sentencia que tiene como uno de sus fines el de unificar la jurisprudencia nacional, tal cual es el de la sentencia de casación, no debe consistir únicamente en citar y transcribir partes motivas completas de sentencias en casos pasados, tal como ocurre en la mayoría de los casos en casación respecto al reajuste pensional de la Ley 6 del año 1992 y su Decreto reglamentario 2108 de igual anualidad.

La Corte Suprema de Justicia no ha configurado una auténtica sentencia de unificación, en la medida en que el asunto presente que posee semejanzas fácticas y jurídicas con casos pasados, no sistematiza sus decisiones anteriores, menos aún pone de presente las subreglas que hasta el momento ha creado en el asunto, con el correspondiente pronunciamiento sobre la continuidad de su vigencia o derogatoria parcial o total, menos aún moldea o crea nuevas justificaciones sobre el problema jurídico concreto. En algunos casos omite en forma absoluta referir cualquier caso pasado, aunque pueda ser análogo; en otros, solo toma ciertos apartes frente a determinada subregla y omite unos distintos que contienen otra. Así, no lleva una sistematización que permita un control de la decisión judicial que procure materialmente tener una providencia que unifique la jurisprudencia nacional. En definitiva, si estas condiciones se incumplen no puede hablarse de una sentencia de unificación, aunque la Ley o la jurisprudencia le otorguen esa denominación. 


\section{Conclusiones de fondo}

La inexistencia de disciplina en la CSJ respecto a la sistematización de sus subreglas viola flagrantemente el principio de previsibilidad del derecho, el derecho a la igualdad y la seguridad jurídica, todos elementos esenciales del derecho fundamental al debido proceso y todos los cuales son presupuestos mínimos en la construcción de una sentencia que pretenda unificar la jurisprudencia nacional.

La construcción de línea jurisprudencial es compleja y es improbable, por múltiples razones, que para resolver un asunto en un despacho y particularmente dentro de este un funcionario sustanciador o un juez o quien desempeñe las funciones de sustanciación realice una investigación como la que aquí se ha pretendido hacer para proferir sentencia. Por ello, se propone que en estos eventos se requiera de una Ley o Decreto Reglamentario que considere seriamente la línea jurisprudencial, para lo cual deberá diseñarse un procedimiento de ajuste del sistema normativo, que permita esa colaboración armónica con el fin de que impere la igualdad, la seguridad jurídica y el principio de previsibilidad del derecho. Ante la imposibilidad de que en un despacho judicial se hagan investigaciones detalladas de los múltiples asuntos en la jurisprudencia, además se hace imperativo que la misma empiece a reconocer el mayor protagonismo y papel de la doctrina dentro del sistema normativo colombiano, permitiéndole ocupar el espacio que le corresponde como auténtico criterio auxiliar.

En semejanza de lo que sería el resultado de ese procedimiento de ajuste del sistema normativo al que se ha hecho referencia, aplicado al caso concreto respecto al ajuste pensional del artículo 116 de la Ley 6 de 1992 y su Decreto reglamentario 2108, la disposición que podría expedirse en consideración de todo el análisis precedente desde las subreglas que se han identificado podría expresarse a través de la formulación de PARÁGRAFOS, los cuales se adicionarían como derecho sustancial o procesal jurisprudencial tanto al contenido del artículo 116 de la Ley 6 del año 1992 como al de su reglamentación, al siguiente tenor:

\section{LEY / DECRETO N. ${ }^{\circ} 1000018$ ENE 2022}

Por la / el cual se ajusta el sistema normativo respecto al reajuste pensional de Ley 6 de 1992 y su Decreto Reglamentario 2108 de 1992

Artículo 1. . AJUSTE A PENSIONES DEL SECTOR PÚBLICO NACIONAL. Para compensar las diferencias de los aumentos de salarios y de las pensiones de jubilación del sector público nacional, efectuados con anterioridad al año 1989, el Gobierno Nacional dispondrá gradualmente el reajuste de 
dichas pensiones, siempre que se hayan reconocido con anterioridad al $1 .^{\circ}$ de enero de 1989.

Los reajustes ordenados en este artículo comenzarán a regir a partir de la fecha dispuesta en el decreto reglamentario correspondiente, y no producirán efecto retroactivo.

Artículo 2. ${ }^{\circ}$. Las pensiones de jubilación del sector público del orden nacional reconocidas con anterioridad al $1 .^{\circ}$ de enero de 1989 que presenten diferencias con los aumentos de salarios serán reajustadas a partir del $1 .^{\circ}$ de enero de 1993, 1994 y 1995 así:

\begin{tabular}{|c|ccc|}
\hline $\begin{array}{c}\text { Año de causación del } \\
\text { derecho a la pensión }\end{array}$ & \multicolumn{3}{|c|}{ Porcentaje del reajuste } \\
$\mathbf{1 9 9 3}-$ & $\mathbf{1 9 9 4}$ - $\mathbf{1 9 9 5}$ \\
\hline 1981 y anteriores 28\% distribuidos así: & 12,0 & 12,0 & 4.0 \\
\hline 1982 hasta 1988 14\%, distribuidos así: & 7,0 & 7,0 & \\
\hline
\end{tabular}

Artículo 3. . Las entidades de previsión social o los organismos o entidades que están encargadas del pago de las pensiones de jubilación tomarán el valor de la pensión mensual a 31 de diciembre de 1992 y le aplicarán el porcentaje del incremento señalado para el año de 1993 cuando se cumplan las condiciones establecidas en el artículo 1. .

El 1. ${ }^{\circ}$ de enero de 1994 y 1995 se seguirá igual procedimiento con el valor de la pensión mensual a 31 de diciembre de los años 1993 y 1994 respectivamente, tomando como base el porcentaje de la columna correspondiente a dichos años señalada en el artículo anterior.

Estos reajustes pensionales son compatibles con los incrementos decretados por el Gobierno Nacional en desarrollo de la Ley 71 de 1988.

Artículo 4. ${ }^{\circ}$. El reconocimiento de los reajustes establecidos en el artículo $1 .^{\circ}$ no se tendrá en cuenta para efectos de la liquidación de mesadas atrasadas.

Artículo 5. ${ }^{\circ}$. Los reajustes ordenados en el presente decreto comenzarán a regir a partir de las fechas establecidas en el artículo $1 .^{\circ}$ y no producirán efectos retroactivos.

Parágrafo 1. A partir de la declaratoria de inexequibilidad del presente artículo, dada a través de la sentencia C-531 de 1995, el ajuste solo aplica a aquellos pensionados que lo solicitaron hasta el 20 de noviembre de 1995. 
Parágrafo 2. Los destinatarios únicos del presente reajuste son aquellas pensiones del sector público nacional. Se excluye de este reajuste los pensionados del orden territorial.

Parágrafo 3. El reajuste ordenado no aplica a aquellos pensionados cuyo régimen jurídico es el propio al sector privado, contenido en el Código Sustantivo del Trabajo, como es el caso de los trabajadores oficiales.

Parágrafo 4. El pensionado debe probar la diferencia existente entre los incrementos decretados por el Gobierno Nacional a los salarios y la pensión y los efectuados a las mesadas pensionales. El ajuste solo será procedente en la medida en que resulten inferiores.

A partir de toda la problemática expuesta en los problemas y desafíos del derecho sustancial y procesal jurisprudencial y su complejidad desde la estructura de la jurisdicción en Colombia, y en particular desde la Jurisdicción Ordinaria, especialidad laboral, se considera que la configuración de la que hemos denominado Cláusula general de fuentes del derecho en Colombia debe considerar no solo la estructura en las distintas jurisdicciones sino comprender toda la racionalidad en la división del poder público y de los particulares; contrario a lo dispuesto hoy en día en el artículo 230 constitucional, que solo refiere a los criterios de la actividad judicial. Desde esta perspectiva, esta cláusula también podría ser denominada Criterios de la actividad judicial, administrativa, legislativa y de los particulares en Colombia, o Cláusula general del sistema normativo en Colombia.

\section{REFERENCIAS}

ACLA Sentencia CAS-SL 9820. (6 de agosto de 1997). Corte Suprema de Justicia. Sala de Casación Laboral. M: Rafael Mendez Arango . Bogotá D.C., Colombia: Expediente 9820.

Álvarez Álvarez, J. C., \& Ramírez Jaramillo, S. (enero-junio de 2016). La nueva interpretación delito de prevaricato por acción de funcionarios judiciales en la jurisprudencia de la Corte Suprema de Justicia. Revista Nuevo Foro Penal, 12(86), 258-263. Obtenido de http://publicaciones.eafit.edu.co/index.php/nuevo-foro-penal/ article/view/3656

Auto 21695. (25 de junio de 2003). Corte Suprema de Justicia. Sala de Casación Laboral. M.P.: Germán G. Valdes Sánchez. Bogotá D.C., Colombia: Radicación No. 21695. Acta No. 45. 
Auto 22287. (26 de agosto de 2003). Corte Suprema de Justicia. Sala de Casación Laboral. M.P.: Germán G. Valdes Sánchez. Bogotá D.C., Colombia: Rad. No. 22287. Acta No. 59.

Auto 22431. (18 de septiembre de 2003). Corte Suprema de Justicia. Sala de Casación Laboral. M.P.: Fernando Vásquez Botero. Bogotá D.C., Colombia: Radicación: 22431. Acta 62.

Auto 22648. (15 de octubre de 2003). Corte Suprema de Justicia. Sala de Casación Laboral. M.P.: Fernando Vásquez Botero. Bogotá D.C., Colombia: Radicación: 22648. Acta $\mathrm{N}^{\circ} 68$.

Auto 23019. (11 de diciembre de 2003). Corte Suprema de Justicia. Sala de Casación Laboral. M.P.: Fernando Vásquez Botero. Bogotá D.C., Colombia: Radicación: 23019. Acta Nro. 80.

Auto 23040. (11 de diciembre de 2003). Corte Suprema de Justicia. Sala de Casación Laboral. M.P.: Fernando Vásquez Botero. Bogotá D.C., Colombia: Radicación: 23040. Acta Nro. 80.

Auto 23269. (3 de febrero de 2004). Corte Suprema de Justicia. Sala de Casación Laboral. M.P.: Fernando Vásquez Botero. Bogotá D.C., Colombia: Radicación: 23269. Acta № 06.

Auto 23337. (10 de febrero de 2004). Corte Suprema de Justicia. Sala de Casación Laboral. M.P.: Fernando Vásquez Botero. Bogotá D.C., Colombia: Radicación: 23337. Acta $\mathrm{N}^{\circ} 08$.

Auto 9047. (10 de julio de 1996). Corte Suprema de Justicia. Sala de Casación Laboral. M.P.: Francisco Escobar Henriquez. Bogotá D.C., Colombia: Radicación No. 9047. Acta No. 28.

Bonett Ortíz, S. A. (2013). El principio dispositivo de la casación. Revista del Instituto colombiano de Derecho Procesal, 39(39), 287-298. Obtenido de http://publicacionesicdp.com/index.php/Revistas-icdp/article/view/38

Cadavid Gómez, I., \& Arenas Gallego, E. (2015). Cartilla del trabajo (10 ed.). Medellín, Colombia: Universidad de Medellín.

Calibuenanoticia. (18 de junio de 2019). Convocan a jubilados para reconocimiento al reajuste pensional. Cali, Colombia. Obtenido de https:/ / calibuenasnoticias.com/ 2019/06/18/convocan-a-jubilados-para-reconocimiento-al-reajuste-pensional/

Canal1. (17 de enero de 2018). Condenan a 10 años de prisión a exalcaldesa de Cúcuta por pago irregular en pensiones. Redacción Internet - Sistema Informativo del Canal 1. 
Bogotá D.C., Colombia. Obtenido de https://canal1.com.co/noticias/justicia/condenan-a-10-anos-de-prision-a-exalcaldesa-de-cucuta-por-pago-irregular-en-pensiones/

CaracolRadio. (15 de diciembre de 2017). Cti captura abogado vinculado a investigación por pago pensional en el municipio. Cúcuta, Colombia. Obtenido de https:/ / caracol.com.co/emisora/2017/12/14/cucuta/1513255359_324208.html

Clavijo Cáceres, D. G., Guerra Moreno, D. L., \& Yañez Meza, D. A. (2014). Método, metodología y técnicas de la investigación aplicadas al derecho. Bogotá D.C., Colombia: Grupo Editorial Ibáñez \& Universidad de Pamplona. Obtenido de http:// fui.corteconstitucional.gov.co/doc/pub/31-08-2017_7b9061_60327073.pdf

Constitución Política. (20 de julio de 1991). El pueblo de Colombia en ejercicio de su poder soberano, representado por sus delegatarios a la Asamblea Nacional Constituyente,...decreta, sanciona y promulga la Constitución Política de 1991. Asamblea Nacional Constituyente. Bogotá D.C., Colombia. Obtenido de https:// www.alcaldiabogota.gov.co/sisjur/normas/Norma1.jsp?i=41249

Decreto 01. (3 de enero de 1984). Presidencia de la República. Por el cual se reforma el Código Contencioso Administrativo. Bogotá D.C., Colombia. Obtenido de https:// www.alcaldiabogota.gov.co/sisjur/normas/Norma1.jsp?i=6543

Decreto 2108. (29 de diciembre de 1992). Presidencia de la República. Por el cual se ajustan las pensiones de jubilación del sector público en el orden Nacional. En desarrollo de las facultades conferidas por el artículo 116 de la Ley $6^{a}$ de 1992. Bogotá D.C., Colombia. Obtenido de https://www.alcaldiabogota.gov.co/sisjur/normas/Norma1 .jsp?i=4894\#1

ElPaís.com.co. (30 de agosto de 2011). Enredos de la Ley que permite reajuste pensional. Unidad Investigativa. Cali, Colombia. Obtenido de https://www.elpais.com.co/ economia/enredos-de-la-ley-que-permite-reajuste-pensional.html

Eltiempo.com. (2 de marzo de 2007). Gobernador del Valle en aprietos porque no se realizó reajuste pensional. El Juzgado de Menores de Cartago ordenó arresto de cinco días y una multa de 10 salarios mínimos legales vigentes contra Angelino Garzón. Redacción El Tiempo. Bogotá D.C., Colombia. Obtenido de http:// www.eltiempo.com/archivo/documento/CMS-3459531

Fiscalía. (12 de mayo de 2015). Fiscalía acusa a exalcalde de Cúcuta por prevaricato y peculado. Boletín 10364. Noticias. Cúcuta, Colombia. Obtenido de https:// www.fiscalia.gov.co/colombia/noticias/fiscalia-acusa-a-exalcalde-de-cucutapor-prevaricato-y-peculado/ 
Fiscalía. (14 de diciembre de 2017). Privado de la libertad abogado condenado por pago irregular de pensiones en la Alcaldía de Cúcuta. Cúcuta, Colombia. Obtenido de https://www.fiscalia.gov.co/colombia/seccionales/privado-de-la-libertadabogado-condenado-por-pago-irregular-de-pensiones-en-la-alcaldia-de-cucuta/

García Vargas, K., \& Pérez Fuentes, C. A. (enero-junio de 2015). La jurisdicción ordinaria y la indeterminación restrictiva que representa el tipo penal de prevaricato en Colombia. Revista Academia \& Derecho, 6(10), 241-272. Obtenido de https:// revistas.unilibre.edu.co/index.php/academia/article/view/355

LaOpinión. (12 de diciembre de 2017). Condenan a exalcaldesa de Cúcuta María Eugenia Riascos. Cúcuta, Colombia. Obtenido de https:/ / www.laopinion.com.co/ cucuta/condenan-exalcaldesa-de-cucuta-maria-eugenia-riascos-145374\#OP

LaOpinión. (16 de enero de 2018). Abogados defienden pago de reajustes a jubilados en 2008. Actualidad. San José de Cúcuta, Colombia. Obtenido de https:// www.laopinion.com.co/politica/abogados-defienden-pago-de-reajustes-jubilados-en-2008-147321\#OP

LaOpinión. (15 de noviembre de 2018). Por el caso de los pensionados, absuelven al exalcalde Villasmil. La Fiscalía lo había acusado por prevaricato por acción y peculado por apropiación en favor de terceros. Cúcuta, Colombia. Obtenido de https://www.laopinion.com.co/politica/por-el-caso-de-los-pensionados-absuelven-al-exalcalde-villasmil-165862\#OP

LaW. (16 de enero de 2018). Exalcaldesa de Cúcuta deberá pagar 10 años de prisión. El fallo será apelado por la defensa. Regiones. Bogotá D.C., Colombia. Obtenido de https:// www.wradio.com.co/noticias/regionales/exalcaldesa-de-cucuta-deberapagar-10-anos-de-prision/20180116/nota/3691216.aspx

Ley 100. (23 de diciembre de 1993). Congreso de la República. Por la cual se crea el sistema de seguridad social integral y se dictan otras disposiciones. Bogotá D.C., Colombia: Diario Oficial. AÑO CXXIX. N. 41148. 23 de diciembre de 1993. Obtenido de http://www.suin-juriscol.gov.co/viewDocument.asp?ruta=Leyes/1635955

Ley 1437. (18 de enero de 2011). Congreso de la República. Por medio de la cual se expide el Código de Procedimiento Administrativo y de lo Contencioso Administrativo. Bogotá D.C., Colombia: Diario Oficial No. 47956 de 18 de enero de 2011. Obtenido de https://www.alcaldiabogota.gov.co/sisjur/normas/Norma1.jsp?i=41249

Ley 1564. (12 de julio de 2012). Congreso de la República. Por medio del cual se expide el Código General del Proceso y se dictan otras disposiciones. Bogotá D.C., Colombia: Diario Oficial 48489 de julio 12 de 2012. Obtenido de https:/ / www.alcaldiabogota. gov.co/sisjur/normas/Norma1.jsp?i=48425 
Ley 4. (21 de enero de 1976). Congreso de la República. Por la cual se dictan normas sobre materia pensional de los sectores público, oficial, semioficial y privado y se dictan otras disposiciones. Bogotá D.C., Colombia: Diario Oficial. Año CXII. N. 34483.5 de febrero de 1976. Obtenido de http://www.suin-juriscol.gov.co/viewDocument. asp?id=1559269

Ley 6. (30 de junio de 1992). Congreso de la República. Por la cual se expiden normas en materia tributaria, se otorgan facultades para emitir títulos de deuda pública interna, se dispone un ajuste de pensiones del sector público nacional y se dictan otras disposiciones. Bogotá D.C., Colombia: Diario Oficial No 40.490, de 30 de junio de 1992. Obtenido de http://www.secretariasenado.gov.co/senado/basedoc/ley_0006_1992_ pr002.html\#116

Ley 71. (19 de diciembre de 1988). Congreso de la República. Por la cual se expiden normas sobre pensiones y se dictan otras disposiciones. Bogotá D.C., Colombia: Diario Oficial. Año CXXV. N. 38624. 22 de diciembre de 1988. Obtenido de http:// www.suin-juriscol.gov.co/viewDocument.asp?ruta=Leyes/1620956

López Medina, D. E. (2008). El derecho de los jueces. Obligatoriedad del precedente constitucional, análisis de sentencias y líneas jurisprudenciales y teoría del derecho judicial (2 ed.). Bogotá D.C., Colombia: Legis Editores S.A.

López Quiroz, A. (julio-diciembre de 2016). Principio de legalidad y prevaricato. Revista DIXI, 18(24), 25-47. Obtenido de https:/ / revistas.ucc.edu.co/index.php/di/ article/view/1521

Pachón Lucas, C. (2014). Los servidores públicos. Y todos los modos de desempeño de funciones públicas en el Estado colombiano (1 ed.). Bogotá D.C., Colombia: Editorial Temis S.A.

RadioRodadero. (20 de octubre de 2016). Pensionados de la Licorera no recibirán pago de Ley 6ta por fallos que niegan reajuste. Departamento, Noticias. Santa Marta, Colombia: Tomado Diario del Magdalena. Obtenido de https:/ / radiomagdalena 1420am.com/pensionados-de-la-licorera-no-recibiran-pago-de-ley-6ta-por-fallosque-niegan-reajuste/

Semana. (13 de mayo de 2015). Acusado exalcalde de Cúcuta por conciliación con pensionados. Cúcuta, Colombia. Obtenido de https://www.semana.com/nacion/ articulo/cucuta-acusado-exalcalde-gustavo-villasmil/427406-3

Sentencia C-009. (18 de enero de 1996). Corte Constitucional. Sala Plena. M.P. Hernando Herrera Vergara. Bogotá D.C., Colombia: Ref.: Proceso No. D-968. Obtenido de http: //www.corteconstitucional.gov.co/relatoria/1996/C-009-96.htm 
Sentencia C-335. (16 de abril de 2008). Corte Constitucional. Sala Plena. M.P.: Humberto Antonio Sierra Porto, Referencia: expedientes D-6943 y D-6946. Bogotá D.C., Colombia. Obtenido de http:/ / www.corteconstitucional.gov.co/relatoria/2008/c-335-08.htm

Sentencia C-400. (3 de julio de 2013). Corte Constitucional. Sala Plena. M.P.: Nilson Pinilla Pinilla. Bogotá D.C., Colombia: Referencia: Expediente D-9392. Obtenido de http://www.corteconstitucional.gov.co/relatoria/2013/C-400-13.htm

Sentencia C-531. (20 de noviembre de 1995). Corte Constitucional. Sala Plena. M.P. Alejandro Martínez Caballero. Bogotá D.C., Colombia: Ref.: Demanda No. D-827. Obtenido de http:/ / www.corteconstitucional.gov.co/relatoria/1995/C-531-95.htm

Sentencia CAS-SL 10180. (11 de noviembre de 1997). Corte Suprema de Justicia. Sala de Casación Laboral. M.P.: Rafael Mendez Arango. Bogotá D.C., Colombia: Radicación 10180. Acta 44 .

Sentencia CAS-SL 10183. (11 de noviembre de 1997). Corte Suprema de Justicia. Sala de Casación Laboral. M.P.: Rafael Mendez Arango. Bogotá D.C., Colombia: Radicación 10183. Acta 44.

Sentencia CAS-SL 12346. (30 de noviembre de 1999). Corte Suprema de Justicia. Sala de Casación Laboral. M.P.: Rafael Mendez Arango. Bogotá D.C., Colombia: Radicación 12346. Acta 44.

Sentencia CAS-SL 14003. (1 de junio de 2000). Corte Suprema de Justicia. Sala de Casación Laboral. M.P.: José Roberto Herrera Vergara. Bogotá D.C., Colombia: Referencia. Expediente No. 14003. Acta No. 22.

Sentencia CAS-SL 15023. (29 de marzo de 2001). Corte Suprema de Justicia. Sala de Casacion Laboral. M.P.: Carlos Isaac Nader. Bogotá D.C., Colombia: RADICACIÓN No. 15023. ACTA No.

Sentencia CAS-SL 18189. (17 de julio de 2002). Corte Suprema de Justicia. Sala de Casación Laboral. M.P. Carlos Isaac Nader. Bogotá D.C., Colombia: Radicación: 18189. Acta No. 28. Obtenido de https://www.funcionpublica.gov.co/eva/gestornor mativo/norma.php?i=6215

Sentencia CAS-SL 18758. (22 de agosto de 2002). Corte Suprema de Justicia. Sala de Casación Laboral. M.P.: José Roberto Herrera Vergara. Bogotá D.C., Colombia: Referencia: Expediente $\mathrm{N}^{\circ} 18758$. Acta $\mathrm{N}^{\circ} 33$.

Sentencia CAS-SL 19928. (13 de mayo de 2003). Corte Suprema de Justicia. Sala de Casación Laboral. M.P. Luis Gonzalo Toro Correa. Bogotá D.C., Colombia: Radicación No. 19928. Acta No. 28. 
Sentencia CAS-SL 21391. (11 de marzo de 2004). Corte Suprema de Justicia. Sala de Casación Laboral. M.P.: Luis Javier Osorio López. Bogotá D.C., Colombia: Radicación $\mathrm{N}^{\circ} 21391$. Acta $\mathrm{N}^{\circ} 16$.

Sentencia CAS-SL 21696. (12 de noviembre de 2003). Corte Suprema de Justicia. Sala de Casación Laboral. M.P.: Eduardo López Villegas. Bogotá D.C., Colombia: Referencia: Expediente No. 21696. Acta No.73.

Sentencia CAS-SL 21821. (13 de noviembre de 2003). Corte Suprema de Justicia. Sala de Casación Laboral. M.P: Eduardo López Villegas. Bogotá D.C., Colombia: Referencia: Expediente No. 21821. Acta $N^{\circ} 73$.

Sentencia CAS-SL 22107. (11 de diciembre de 2003). Corte Suprema de Justicia. Sala de Casación Laboral. M.P. Eduardo López Villegas. Bogotá D.C., Colombia: Referencia: Expediente No. 22107. Acta No. 80. Obtenido de https://www.alcaldia bogota.gov.co/sisjur/normas/Norma1.jsp?i=11944\&dt=S

Sentencia CAS-SL 22291. (10 de diciembre de 2004). Corte Suprema de Justicia. Sala de Casación Laboral. M.P.: Isaura Vargas Díaz. Bogotá D.C., Colombia: Radicación No. 22291. Acta No. 108.

Sentencia CAS-SL 22360. (26 de marzo de 2004). Corte Suprema de Justicia. Sala de Casación Laboral. M.P. Eduardo López Villegas. Bogotá D.C., Colombia: Referencia: Expediente No. 22360. Acta $\mathrm{N}^{\circ} 20$.

Sentencia CAS-SL 22893. (14 de abril de 2005). Corte Suprema de Justicia. Sala de Casación Laboral. M.P.: Francisco Javier Ricaurte Gómez. Bogotá D.C., Colombia: Radicación Nro. 22893. Acta Nro. 41.

Sentencia CAS-SL 23058. (10 de diciembre de 2004). Corte Suprema de Justicia. Sala de Casación Laboral. M.P. Isaura Vargas Díaz. Bogotá D.C., Colombia: Radicación No. 23058. Acta No. 108. Obtenido de https://www.alcaldiabogota.gov.co/sisjur/ normas/Norma1.jsp?i=15895\&dt=S

Sentencia CAS-SL 23253. (13 de octubre de 2004). Corte Suprema de Justicia. Sala de Casación Laboral. M.P.: Luis Javier Osorio Botello. Bogotá D.C., Colombia: Radicación $\mathrm{N}^{\circ} 23253$. Acta $\mathrm{N}^{\circ} .84$.

Sentencia CAS-SL 23434. (25 de mayo de 2005). Corte Suprema de Justicia. Sala de Casación Laboral. M.P.: Francisco Javier Ricaurte Gómez. Bogotá D.C., Colombia: Radicación No. 23434.

Sentencia CAS-SL 23543. (16 de marzo de 2005). Corte Suprema de Justicia. Sala de Casación Laboral. M.P.: Isaura Vargas Díaz. Bogotá D.C., Colombia: Radicación No. 23543. Acta No. 27. 
Sentencia CAS-SL 23667. (14 de septiembre de 2004). Corte Suprema de Justicia. Sala de Casación Laboral. M.P.: Eduardo López Villegas . Bogotá D.C., Colombia: Referencia: Expediente No. 23667. Acta No. 70.

Sentencia CAS-SL 23800. (04 de mayo de 2005). Corte Suprema de Justicia. Sala de Casación Laboral. M.P.: Isaura Vargas Díaz. Bogotá D.C., Colombia: Radicación No. 23800. Acta No 47.

Sentencia CAS-SL 23883. (11 de agosto de 2004). Corte Suprema de Justicia. Sala de Casación Laboral. M.P.: Eduardo López Villegas. Bogotá D.C., Colombia: Referencia: Expediente No. 23883. Acta No. 58.

Sentencia CAS-SL 23938. (12 de abril de 2005). Corte Suprema de Justicia. Sala de Casación Laboral. M.P.: Isaura Vargas Díaz. Bogotá D.C., Colombia: Radicació No. 23938. Acta No. 37.

Sentencia CAS-SL 24030. (30 de septiembre de 2004). Corte Suprema de Justicia. Sala de Casación Laboral. M.P.: Eduardo López Villegas. Bogotá D.C., Colombia: Referencia: Expediente No. 24030. Acta No. 78.

Sentencia CAS-SL 24142. (1 de marzo de 2005). Corte Suprema de Justicia. Sala de Casación Laboral. M.P.: Carlos Isaac Nader. Bogotá D.C., Colombia: Radicació Nro. 24142. Acta Nro 23.

Sentencia CAS-SL 24143. (13 de octubre de 2004). Corte Suprema de Justicia. Sala de Casación Laboral. M.P.: Eduardo López Villegas. Bogotá D.C., Colombia: Referencia: Expediente No. 24143. Acta No. 84.

Sentencia CAS-SL 24153. (22 de agosto de 2005). Corte Suprema de Justicia. Sala de Casación Laboral. M.P.: Francisco Javier Ricaurte Gómez. Bogotá D.C., Colombia: Radiación No. 24153. Acta No 70.

Sentencia CAS-SL 24154. (23 de septiembre de 2004). Corte Suprema de Justicia. Sala de Casación Laboral. M.P.: Eduardo López Villegas. Bogotá D.C., Colombia: Referencia: Expediente No. 24154. Acta No. 75.

Sentencia CAS-SL 24303. (13 de abril de 2005). Corte Suprema de Justicia. Sala de Casación Laboral. M.P. Luis Javier Osorio López. Bogotá D.C., Colombia: Radicación $\mathrm{N}^{\circ} 24303$. Acta $\mathrm{N}^{\circ} 41$.

Sentencia CAS-SL 24452. (10 de mayo de 2005). Corte Suprema de Justicia. Sala de Casación Laboral. M.P. Luis Javier Osorio López. Bogotá D.C., Colombia: Radicación $\mathrm{N}^{\circ}$ 24452. Acta $\mathrm{N}^{\circ} .48$. 
Sentencia CAS-SL 25013. (14 de septiembre de 2005). Corte Suprema de Justicia. Sala de Casación Laboral. M.P. Isaura Vargas Díaz. Bogotá D.C., Colombia: Radicación No. 25013. Acta No. 78.

Sentencia CAS-SL 26762. (1 de agosto de 2006). Corte Suprema de Justicia. Sala de Casación Laboral. M.P.: Isaura Vargas Díaz. Bogotá D.C., Colombia: Radicación No. 26762. Acta No. 54.

Sentencia CAS-SL 27616. (23 de marzo de 2007). Corte Suprema de Justicia. Sala de Casacion Laboral. M.P. Francisco Javier Ricaurte Gómez. Bogotá D.C., Colombia: Radicación No. 27616. Acta No. 19.

Sentencia CAS-SL 29246. (3 de agosto de 2007). Corte Suprema de Justicia. Sala de Casación Laboral. M.P. Francisco Javier Ricaurte Gómez. Bogotá D.C., Colombia: Rad. No. 29246. Acta $\mathrm{N}^{\circ} 64$.

Sentencia CAS-SL 35895. (1 de septiembre de 2009). Corte Suprema de Justicia. Sala de Casación Laboral. M.P.: Elsy del Pilar Cuello Calderón. Bogotá D.C., Colombia: Rad. No. 35895. Acta No. 34.

Sentencia CAS-SL 36640. (1 de noviembre de 2011). Corte Suprema de Justicia. Sala de Casación Laboral. M.P.: Luis Gabriel Miranda Buelvas. Bogotá D.C., Colombia: Radicación No. 36640. Acta No. 037.

Sentencia CAS-SL 37693. (25 de julio de 2012). Corte Suprema de Justicia. Sala de Casación Laboral. M.P. Elsy del Pilar Cuello Calderón. Bogotá D.C., Colombia: Radicación No. 37693. Acta No. 26.

Sentencia CAS-SL 39871. (27 de junio de 2012). Corte Suprema de Justicia. Sala de Casación Laboral. M.P.: Carlos Ernesto Molina Monsalve. Bogotá D.C., Colombia: Radicación $\mathrm{N}^{\circ} 39871$. Acta $\mathrm{N}^{\circ} 22$.

Sentencia CAS-SL 41873. (20 de febrero de 2013). Corte Suprema de Justicia. Sala de Casación Laboral. M.P. Rigoberto Echeverri Bueno. Bogotá D.C., Colombia: Radicación No. 41873. Acta No. 05. Obtenido de https:/ / normativa.colpensiones.gov.co/ colpens/docs/csj_scl_41873(20_02_13)_2013.htm

Sentencia CAS-SL 44514. (04 de julio de 2012). Corte Suprema de Justicia. Sala de Casación Laboral. M.P.: Luis Gabriel Miranda Buelvas. Bogotá D.C., Colombia: Radicación No. 44514. Acta No. 023.

Sentencia CAS-SL 47697. (12 de noviembre de 2014). Corte Suprema de Justicia. Sala de Casación Laboral. M.P. Rigoberto Echeverri Bueno. Bogotá D.C., Colombia: SL157752014. Radicación n. ${ }^{\circ} 47697$. Acta 41. 
Sentencia CAS-SL 58896. (29 de mayo de 2018). Corte Suprema de Justicia. Sala de Casación Laboral. M.P.: Muñoz Segura. Bogotá D.C., Colombia: Radicación nº 58896. Acta 16. SL2627-2018.

Sentencia CAS-SL 65377. (14 de agosto de 2018). Corte Suprema de Justicia. Sala de Casación Laboral. M.P.: Giovanni Francisco Rodríguez Jiménez. Bogotá D.C., Colombia: Radicación n. ${ }^{\circ}$ 65377. Acta 27. SL3481-2018.

Sentencia CAS-SL 65651. (8 de octubre de 2019). Corte Suprema de Justicia. Sala de Casación Laboral. M.P.: Giovanni francisco Rodríguez Jiménez. Bogotá D.C., Colombia: Radicación n. ${ }^{\circ}$ 65651. Acta 35. SL4366-2019.

Sentencia CAS-SL 66402. (11 de febrero de 2015). Corte Suprema de Justicia. Sala de Casación Laboral. M.P. Jorge Mauricio Burgos Ruiz. Bogotá D.C., Colombia: Radicado No. 66402. SL1361-2015. Acta 03.

Sentencia CAS-SL 67051. (10 de abril de 2019). Corte Suprema de Justicia. Sala de Casación Laboral. M.P.: Dolly Amparo Caguasango Villota. Bogotá D.C., Colombia: Radicación n. ${ }^{\circ}$ 67051. Acta 12. SL1339-2019.

Sentencia CAS-SL 69401. (14 de agosto de 2019). Corte Suprema de Justicia. Sala de Casación Laboral. M.P.: Jorge Prada Sánchez. Bogotá D.C., Colombia: Radicación n. ${ }^{\circ}$ 69401. Acta 27. SL3241-2019.

Sentencia CAS-SL 9286. (18 de abril de 1997). Corte Suprema de Justicia. Sala de Casación Laboral. M.P.: Rafael Méndez Arango. Bogotá D.C., Colombia: Radicación 9286. Acta 14.

Sentencia CAS-SL 9607. (15 de agosto de 1997). Corte Suprema de Justicia. Sala de Casación Laboral. M.P.: Ramón Zuñiga Valverde. Bogotá D.C., Colombia: ACTA N ${ }^{\circ}$ 33. RADICACION 9607.

Sentencia CAS-SL 9647. (24 de julio de 1997). Corte Suprema de Justicia. Sala de Casación Laboral. M.P.: Rafael Méndez Arango. Bogotá D.C., Colombia: Radicación 9647. Acta 30 .

Sentencia CAS-SL 9820. (6 de agosto de 1997). Corte Suprema de Justicia. Sala de Casación Laboral. M.P.: Rafael Méndez Arango. Bogotá D.C., Colombia: Radicación 9820. Acta 31.

Sentencia CAS-SP 39456. (10 de abril de 2013). Corte Suprema de Justicia. Sala de Casación Penal. M.P.: José Luis Barceló Camacho. Bogotá D.C., Colombia: Radicación 39456. Aprobado acta $N^{\circ} 106$. 
Sentencia CAS-SP 46884. (16 de noviembre de 2016). Corte Suprema de Justicia. Sala de Casación Penal. M.P.: Luis Antonio Hernández Barbosa. Bogotá D.C., Colombia: Radicación: 46884. SP16574-2016.

Sentencia CAS-SP 49777. (16 de agosto de 2017). Corte Suprema de Justicia. Sala de Casación Penal. M.P.: Gustavo Enrique Malo Fernández. Bogotá D.C., Colombia: Radicación: 49777. SP12323-2017.

Sentencia CAS-SP 50131. (24 de julio de 2017). Corte Suprema de Justicia. Sala de Casación Penal. M.P.: Eugenio Fernández Carlier. Bogotá D.C., Colombia: Radicación: 50131. SP10762-2017.

Sentencia CAS-SP 51117. (23 de mayo de 2018). Corte Suprema de Justicia. Sala de Casación Penal. M.P.: Fernando Alberto Castro Caballero. Bogotá D.C., Colombia: Radicación: 51117. SP1616-2018.

Sentencia CAS-SP 51142. (21 de febrero de 2018). Corte Suprema de Justicia. Sala de Casación Penal. M.P.: Patricia Salazar Cuellar. Bogotá D.C., Colombia: Radicación: 51142. SP364-2018.

Sentencia CAS-SP 53765. (3 de abril de 2019). Corte Suprema de Justicia. Sala de Casación Penal. M.P.: Eugenio Fernández Carlier. Bogotá D.C., Colombia: Radicación 53765. DP1176-2019. Aprobado mediante acta Nº 83.

Sentencia NPI 0038-(479)/98. (15 de abril de 1999). Consejo de Estado. Sala de lo Contencioso Administrativo. Sección Segunda. C.P.: Carlos Arturo Orjuela Góngora. Bogotá D.C., Colombia: Expediente No. 0038- (479) /98.-. Obtenido de http://www.alcaldiabogota.gov.co/sisjur/normas/Norma1.jsp?i=9677

Sentencia NPI 11636. (11 de junio de 1998). Consejo de Estado. Sala de lo Contencioso Administrativo. Sección Segunda. C.P.: Nicolás Pájaro Peñaranda. Bogotá D.C., Colombia: Expediente $\mathrm{N}^{\circ} 11636$. Obtenido de No se registra

Sentencia NRD 1920-13. (10 de octubre de 2013). Consejo de Estado. Sala de lo Contencioso Administrativo. Sección Segunda. Subsección B. C.P. Bertha Lucia Ramírez de Páez (E). Bogotá D.C., Colombia: Radicación número: 76001-23-31-000-2010-0081601(1920-13). Obtenido de http:/ / www.consejodeestado.gov.co/documentos/boletines/139/S2/76001-23-31-000-2010-00816-01(1920-13).pdf

Taruffo, M. (2014). Precedente y jurisprudencia. (D. M. Ramírez Carvajal, Ed., \& D. M. Ramírez Carvajal, Trad.) Revista Temas Procesales(29), 11-33.

Troncoso Mojica, J. A. (Enero-Junio de 2015). El precedente judicial y el principio de legalidad penal en la contratación pública colombiana. Revista Academia E Derecho, 6(10), 91-118. doi:https://doi.org/10.18041/2215-8944/academia.10.350 
Yáñez Meza, D. A. (2013). El derecho de la jurisdicción. Concepciones discutibles y estudio sobre la institución en la vértebra axiológica del juzgar (1 ed.). Cúcuta, Colombia: Universidad Libre.

Yañez Meza, D. A. (2016). Elementos de la democracia en la función judicial desde el Código General del Proceso y el Código de Procedimiento Administrativo y de lo Contencioso Administrativo. En Código General del Proceso y reformas procesales en Iberoamérica (págs. 269-310). Bogotá D.C.: Universidad Libre -Cúcuta- \& Grupo Editorial Ibáñez.

Yañez Meza, D. A. (2017). El derecho al reajuste pensional de la Ley 6 del año 1992: un dilema jurídico para la administración pública territorial desde el derecho de los jueces. Revista Advocatus, 14(28), 45-77. Obtenido de https://revistas.unilibre. edu.co/index.php/advocatus/article/view/887

Yañez Meza, D. A. (2017). Integración de disposiciones procesal en Colombia: desde los ámbitos especiales de aplicación al ámbito ordinario o residual. Derecho procesal colombiano. Tendencias, críticas y propuestas. En homenaje al maestro Jairo Parra Quijano, 1, 323-329. Bogotá D.C., Colombia: Instituto colombiano de Derecho Procesal. 
